San Jose State University

SJSU ScholarWorks

Master's Theses

Master's Theses and Graduate Research

Summer 2019

\title{
The Energetic Cost of Anthropogenic Disturbance on the Southern Sea Otter (Enhydra lutris nereis)
}

Heather Elizabeth Barrett

San Jose State University

Follow this and additional works at: https://scholarworks.sjsu.edu/etd_theses

\section{Recommended Citation}

Barrett, Heather Elizabeth, "The Energetic Cost of Anthropogenic Disturbance on the Southern Sea Otter (Enhydra lutris nereis)" (2019). Master's Theses. 5023.

DOI: https://doi.org/10.31979/etd.62cf-qybg

https://scholarworks.sjsu.edu/etd_theses/5023

This Thesis is brought to you for free and open access by the Master's Theses and Graduate Research at SJSU ScholarWorks. It has been accepted for inclusion in Master's Theses by an authorized administrator of SJSU ScholarWorks. For more information, please contact scholarworks@sjsu.edu. 


\author{
A Thesis \\ Presented to \\ The Faculty of Moss Landing Marine Laboratories \\ San José State University \\ In Partial Fulfillment \\ of the Requirements for the Degree \\ Master of Science
}

by

Heather E. Barrett

August 2019 
(C) 2019

Heather E. Barrett

ALL RIGHTS RESERVED 
The Designated Thesis Committee Approves the Thesis Titled

\section{THE ENERGETIC COST OF ANTHROPOGENIC DISTURBANCE ON THE} SOUTHERN SEA OTTER (ENHYDRA LUTRIS NEREIS)

by

Heather E. Barrett

\section{APPROVED FOR THE DEPARTMENT OF MARINE SCIENCE}

SAN JOSÉ STATE UNIVERSITY

August 2019

Birgitte I. McDonald, Ph.D. Moss Landing Marine Laboratories

Thomas P. Connolly, Ph.D. Moss Landing Marine Laboratories

M. Tim Tinker, Ph.D. University of California, Santa Cruz 


\title{
ABSTRACT
}

\section{THE ENERGETIC COST OF ANTHROPOGENIC DISTURBANCE ON THE SOUTHERN SEA OTTER (ENHYDRA LUTRIS NEREIS)}

\author{
by Heather E. Barrett
}

With increased human populations and tourism in coastal areas, there is greater potential for disturbance of marine wildlife. Having high metabolic rates, sea otters (Enhydra lutris nereis) are at risk of increased energetic costs due to disturbance. To investigate these effects, sea otter activity in response to potential disturbance stimuli was recorded over three years, at three California locations: Monterey, Moss Landing, and Morro Bay. A hidden Markov Model was developed to examine how activity varies as a function of location, group size, pup to adult ratio, kelp canopy, and occurrence of and proximity to disturbance stimuli. Results were combined with published estimates of activity-specific metabolic rates, translating activity change into energetic costs. The effects of disturbance stimuli on sea otter behavior appear location specific, and vary non-linearly with distance from disturbance stimuli. The model quantifies the distancedisturbance relationship, calculating distance at which the likelihood of disturbance is low (i.e. averaged across locations, there is $<10 \%$ potential for disturbance when stimuli are $>54$ m away). Energetic costs $(\mathrm{kJ})$ for Monterey, Moss Landing, and Morro Bay (given six small-craft approaches of $\leq 20 \mathrm{~m}$ for a $27.7 \mathrm{~kg}$ male otter in kelp, group size 10 , and pup ratio 0.5 ) are expected to increase by $210.1 \mathrm{~kJ} \pm 80.76,160.07 \mathrm{~kJ} \pm 65.24$ and $58.44 \mathrm{~kJ} \pm 23.66$, respectively. Our analyses represent a novel approach for estimating behavioral responses and energetic costs of disturbance, furthering understanding of how human activities impact sea otters and providing a sound scientific basis for management. 


\section{ACKNOWLEDGMENTS}

Funding for student research is critical. To Jenny and Marshall White, I owe my graduate degree to you. I would not have been able to pursue a masters without your generous support. I would also like to thank the Dr. Earl H. Myers \& Ethel M. Myers Oceanographic Marine Biology Trust, the San Jose State University Alumni Department of Science Fellowship, and the Polka Dot Foundation for their financial support during my graduate project.

I am especially thankful to my advisor, Gitte McDonald, for her guidance. It has been an honor to be an early member of her lab. Thank you for always making time to guide me through, and for all of the unique field opportunities. I would also like to thank my other two committee members, Tom Conolly and Tim Tinker, for their invaluable input on my thesis. Tim's modeling genius and Tom's statistical expertise made this happen. My deepest gratitude to Tim for the zoom meetings, the emails regarding MatLab code to guide me through the complex world of Markov Models, and for bestowing me the use of an amazing model.

A particular thank you to Gena Bentall and the Sea Otter Savvy volunteers, for without their dedication, this project truly would not exist. They spent endless hours watching sea otters and recording behavior, and their sheer number of hours in the field produced an impressive dataset that could accommodate a complex model. Gena, you have been my greatest mentor since my days at UCSC and I'm so grateful for your friendship. Your opinion matters most. 
The MLML community has also supported me through this process. I would like to thank Mason Cole, Sharon Hsu, Jacoby Baker, Jenni Johnson, Brijonnay Madrigal, Shawn Hannah, Kate High and all of those in the Marine Vertebrate Ecology Lab. You have become family. Our adventures in and out of school made getting through possible. A special shout out to Stephanie Flora for all of her MatLab guidance, your help was invaluable.

Lastly, thank you to my husband Lewis and the rest of my amazing family. Your love and support through this process kept me going. To my parents, you never gave up on me. Thank you for always being there, and for all of your guidance through the years. Dad, being able to consider you as part of my personal 'committee' meant the world. To Lewis, when it felt too daunting you gave me strength to push through despite the hurdles. I cannot believe we got engaged, married, bought a house, commuted, and somehow went to school all at the same time. The last four years were a test and we passed with flying colors. I love you, and I look forward to what comes next. 


\section{TABLE OF CONTENTS}

List of Tables............................................................. vii

List of Figures................................................................ viii

List of Abbreviations............................................................

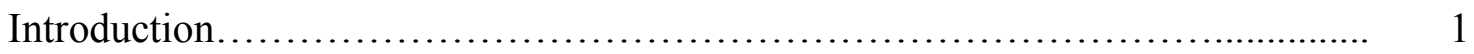

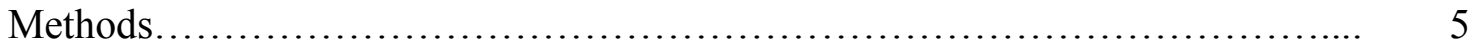

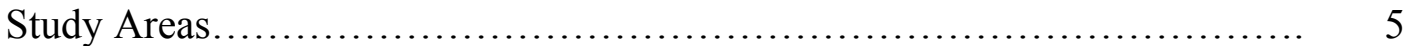

Behavioral Observations............................................. 6

Statistical Analysis................................................. 9

Process Model......................................................... 9

Observation Model................................................ 12

Prior Model..................................................... 12

Summarizing Model Results..................................... 13

Calculating Energetic Costs...................................... 14

Field Metabolic Rates (FMR) ................................ 15

Net Cost of Disturbance........................................ 16

Results ..................................................................... 18

Disturbance Effects................................................ 18

Distance Effects................................................... 22

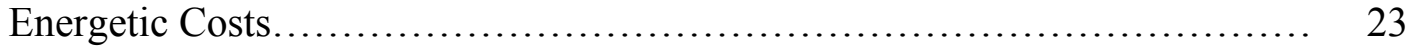

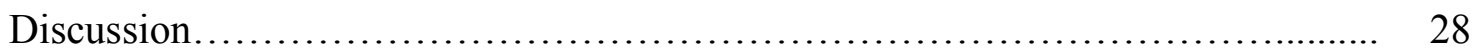

Variation in Disturbance.................................................... 28

Distance Effect.................................................. $\quad 30$

Energetic Cost of Disturbance.......................................... 32

Conclusion.......................................................... 34

References................................................................. 35

Appendix..................................................................... 39 


\section{LIST OF TABLES}

Table 1. (A) Potential Disturbance Stimuli with Vessel Size Classification

(B) Sea Otter Ethogram ................................. 


\section{LIST OF FIGURES}

Figure 1. (A) The southern sea otter range along the California coast showing the three scan locations.......................

Figure 2. Relative Disturbance Effect (indicator of sea otter sensitivity to disturbance) across study sites given: group size $=10$, pup ratio $=$ 0.5 , kelp canopy $=0.5$, time of day $=$ morning, previous activity state $\left(A_{i, j, t-1}\right)=0.5$, and small craft stimulus. . . . . . . . .

Figure 3. Relative Disturbance Effect (indicator of sea otter sensitivity to disturbance) across study locations Moss Landing (turquoise); Monterey (blue); Morro Bay (yellow) given: group size $=10$, pup ratio $=0.5$, kelp canopy $=0.5$, time of day $=$ morning, previous activity state $\left(A_{i, j, t-1}\right)=0.5$, and small craft stimulus............

Figure 4. Covariate effects are compared using Relative Disturbance Effect (indicator of sea otter sensitivity to disturbance) and differing values of each covariate (group size $=20 \mathrm{vs,} 1$, pup ratio $=1 \mathrm{vs}$. 0 , kelp canopy $=1$ vs. 0 , time of day $=$ morning vs. early afternoon vs. late afternoon) while holding all other covariates fixed at their standardized values (group size $=10$, pup ratio $=0.5$, kelp canopy $=0.5$, time of day $=$ morning, previous activity state $\left(A_{i, j, t-1}\right)=0.5$, and small craft stimulus)....................

Figure 5. Mean expected activity level for sea otters is evaluated across covariates to assess which sets of conditions were more associated with resting behavior and thus greater potential for disturbance.....

Figure 6. The Relative Potential Disturbance Effect (PD) for sea otters at varying distances given different locations: Moss Landing (turquoise), Monterey (blue), Morro Bay (yellow), Average (black)..................................................

Figure 7. (A) The probability of a sea otter being active with six disturbances (small craft stimulus) with a $20 \mathrm{~m}$ critical distance.

Figure 8. The cumulative energetic cost $(\mathrm{kJ})$ for a $27.7 \mathrm{~kg}$ male sea otter in Monterey given six disturbances of a stimulus (small craft) at 15 $\mathrm{m}, 20 \mathrm{~m}, 30 \mathrm{~m}$, and $50 \mathrm{~m}$ critical distances 
Figure 9. The average energetic cost $(\mathrm{kJ}) \pm \mathrm{SD}$ for an average male $27.7 \mathrm{~kg}$ sea otter (filled) and an average female $19.89 \mathrm{~kg}$ sea otter (textured), given six disturbances (small craft) across locations and varying critical distances:15 m (blue), $20 \mathrm{~m}$ (green), $30 \mathrm{~m}$ (lime), $50 \mathrm{~m}$ (yellow)...................................... 


\section{LIST OF ABBREVIATIONS}

CARO - Monterey cannery row

$\mathrm{CI}$ - credible interval

FMR - field metabolic rate

Grpsz - group size

HMM - hidden Markov model

HOPK - Monterey Hopkins

JTTY - Moss Landing jetty road

Kelp - kelp canopy ratio

MBCT - Morro Bay target rock

MBHM - Morro Bay harbor mouth

MBTP - Morro Bay T-pier

OP - Monterey otter point

PD - Potential Disturbance Effect

PM1 - early afternoon

PM2 - late afternoon

Pup - pup ratio

RDE - Relative Disturbance Effect

SEBE - Moss Landing seal bend

SOS - Sea Otter Savvy

VO2 - volume of Oxygen

WILD - Moss Landing wildlife platform 


\section{Introduction}

Human-wildlife interactions are a growing concern in conservation policy and management (Benham, 2006; Curland, 1997; Houston, Prosser, \& Sans, 2012). As outdoor recreation increases there is a consequent rise in human-wildlife encounters (Houston et al., 2012). These encounters often cause animals to change behavior or experience a physiological response (Bejder, Samuels, Whitehead, Finn, \& Allen, 2009; Houston et al., 2012; Nowacek \& Wells, 2001; Weimerskirch et al., 2002). Responses may include avoidance (Lunn, Stirling, Andriashek, \& Richardson, 2004; Martin et al., 2010), reduced feeding activity (Lusseau, Bain, Williams, \& Smith, 2009; Williams, Lusseau, \& Hammond, 2006), and stimulation of a stress response (Dantzer, Fletcher, Boonstra, \& Sheriff, 2014; Hill, Wyse, \& Anderson, 2004), which can have hidden physiological consequences (Culik, Adelung, \& Woakes, 1990; Weimerskirch et al., 2002). These consequences are not well understood by recreationalists or management agencies (Houston et al., 2012), and as coastal outdoor recreation increases, so may the impacts to wildlife.

To determine how human disturbance impacts wildlife, management agencies must quantify the effects of anthropogenic disturbance (Beale, 2007; Benham, 2006; Curland, 1997). However, the methods used to quantify disturbance vary (Benham, 2006; Culik et al., 1990; Curland, 1997; Weimerskirch et al., 2002; R. Williams et al., 2006), with most studies focusing on behavioral responses (Benham, 2006; Curland, 1997) and ignoring the energetic costs of the response. Linking the behavioral response to metabolic costs is 
essential to determine the energetic impacts of disturbance for high-risk populations and ecologically significant species such as the southern sea otter (Enhydra lutris nereis).

Sea otters are considered to be at high risk of disturbance because of their accessibility and appeal to ecotourists (Benham, 2006; Curland, 1997). Frequent disturbance associated with tourism activities is a concern because of sea otter's unusual biology: as the most recently evolved marine mammal, the sea otter lacks many adaptations for a fully marine lifestyle (Riedman \& Estes, 1990; Yeates, Williams, \& Fink, 2007). Due to their small size, sea otters have a large surface area to volume ratio compared to most marine mammals. Furthermore, they live in cold water. This combination results in high rates of heat loss, leading to high energetic costs to maintain body temperature (Yeates et al., 2007). Consequently, sea otters exhibit the highest mass-specific metabolic rate of any marine mammal (Thometz, Tinker, Staedler, Mayer, \& Williams, 2014; Yeates et al., 2007). To meet this energetic demand, sea otters must consume large amounts of food, spending up to $45 \%$ of their time feeding, and most of their remaining time budget is spent resting in order to reduce costs (Thometz et al., 2014; Yeates et al., 2007). Reduced rest time and increased activity due to chronic human disturbance may jeopardize an already precarious energetic balance.

Growing interest and popularity of interacting with marine mammals challenge wildlife managers to protect species while allowing the public to enjoy and learn about wildlife (Hoyt, 2001; Sorice, Shafer, \& Scott, 2003). Sea otters are protected by the Endangered Species Act (The Endangered Species Act of 1973, 1973) and Marine Mammal Protection Act (The Marine Mammal Protection Act of 1972, 1978). The 
Marine Mammal Protection Act protects sea otters from disturbances 'causing disruption of behavioral patterns, including, but not limited to, migration, breathing, nursing, breeding, feeding, or sheltering' (The Marine Mammal Protection Act of 1972, 1978). However, this definition is broad, and enforcing this policy is challenging for coastal species (Sorice et al., 2003).

Another complicating issue is that the distance at which a potential disturbance stimulus affects an animal's behavior varies between species (Sorice et al., 2003; Tarlow $\&$ Blumstein, 2007), and even among populations within the same species (Benham, 2006; Sorice et al., 2003). For sea otters, we expect that their response to potential disturbances may depend on the type of stimulus, the distance from stimulus to otter, habitat type, and the geographic and demographic context. Sea otters preferentially use areas with kelp canopy for resting (Riedman \& Estes, 1990). Thus, disturbances in kelp may be more problematic than open water areas, where otters are more likely to already be active. Certain locations may experience higher levels of disturbance, especially if near coastal access points and tourism hot spots. Group size and composition may also be relevant: an otter in a large group within kelp canopy is more likely to be resting than a single sea otter outside of kelp canopy (Riedman \& Estes, 1990), and thus more susceptible to being disturbed. To fully explore the energetic cost of disturbance, it is critical to quantify and control for all of these covariates.

The goals of this project were to collect behavioral data from tourism hot spots and determine 1) the frequency of disturbance at different locations and how the degree of disturbance varies with distance to stimuli, 2) the factors that influence sea otter response, 
and 3) the energetic cost of disturbance. We predicted that sea otters in areas of high tourism would experience a response to disturbance through increased activity. The type of disturbance (i.e. kayak) and the distance of the stimulus would also impact the degree of sea otter response and consequent energetic cost. Moreover, we predicted that behavioral responses will be influenced by various covariates, including location, group size, presence of kelp canopy and pups, and time of day. We recognize that disturbance events are often not instantaneous, but rather occur over an extended period of time with potential delays, and that the context of the disturbance (i.e. behavior of an individual sea otter before and after disturbance) is also relevant. To account for these complexities, we use a hidden Markov model framework (Taylor, 2017) to describe sea otter behavior including the potential responses to disturbance - as a dynamic process. We fit the Markov model to empirical data on sea otter activity and disturbance stimuli collected using instantaneous scan sampling. Finally, we combine model results with published sea otter metabolic rates (Yeates et al., 2007) to produce the first quantitative estimate of the physiological costs of human disturbance on sea otters. 


\section{Methods}

\section{Study Areas}

Behavioral observations were conducted at three locations in California: Monterey, Moss Landing, and Morro Bay. At each location we collected behavioral data at three sites, for a total of 9 sites (Figure 1). Locations were selected to represent different sea otter habitats, including open coast (Monterey) and protected harbor habitats (Moss Landing, Morro Bay). Sites within each location were selected to represent a range of potential levels of human interaction, although all sites were known to be at some risk of disturbance based on proximity to disturbance sources (boat launches, beach access points). Otter abundance and distribution at each site varied through the year. In the case of open coast sites, the availability of kelp canopy varied seasonally (large winter storms can remove much of the surface kelp canopy), which in turn affected the tendency of sea otters to rest in kelp. This seasonal trend was not evident in protected harbors without kelp: at jetty (JTTY) and seal bend (SEBE), where sea otters form large resting groups in all seasons. Observations were conducted from shore-based stations (including public viewing areas) near each site, and all procedures followed a protocol approved by the San Jose State University Institutional Animal Care and Use Committee (IACUC Reference \# EX-02052018). 


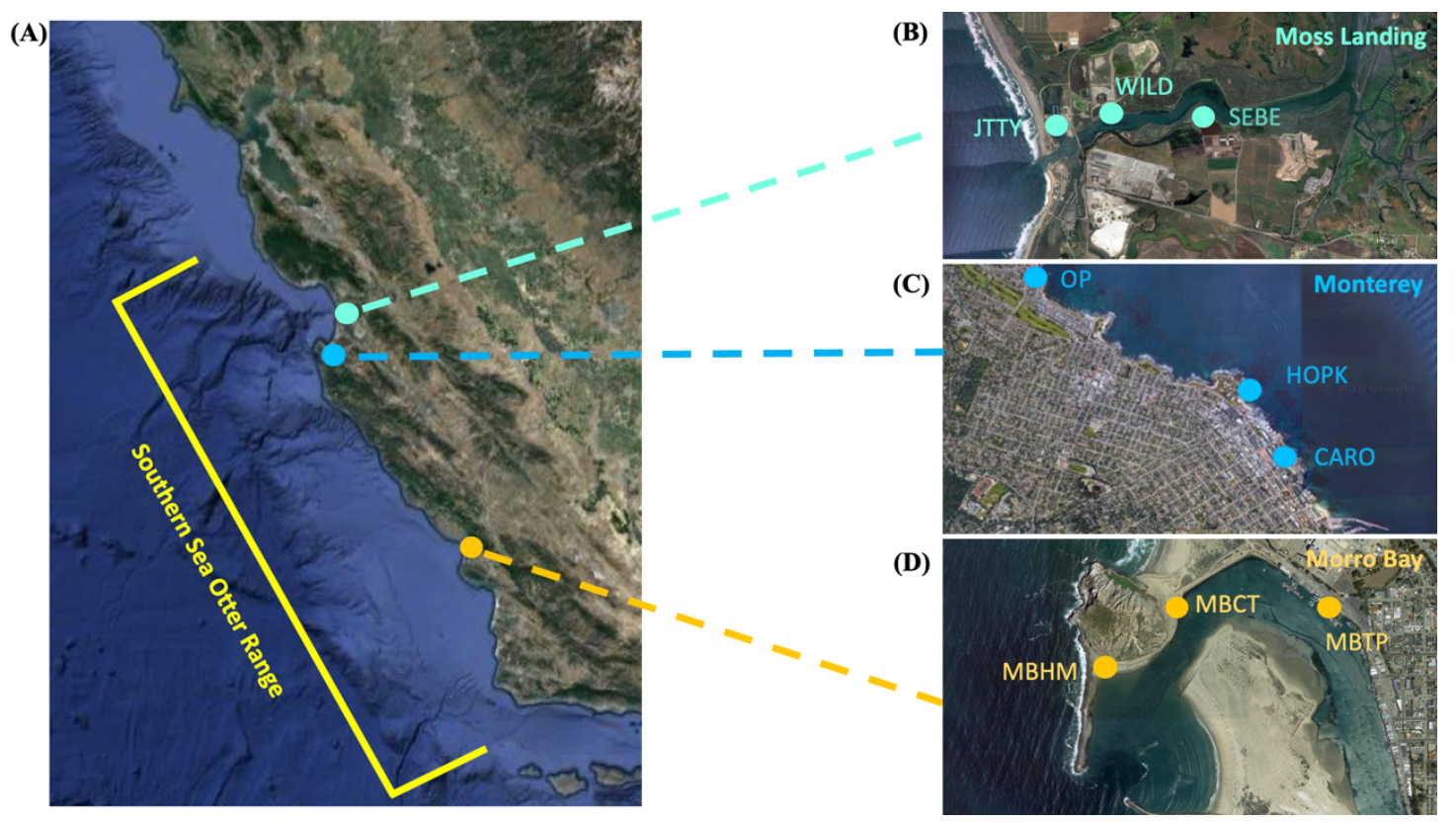

Figure 1. (A) The southern sea otter range along the California coast showing the three scan locations. (B) Moss Landing's public viewing scan sites in turquoise: jetty road (JTTY) (36 $48^{\circ} 34.7^{\prime \prime} \mathrm{N} 121^{\circ} 47^{\prime} 17.5^{\prime}$ 'W), seal bend (SEBE) $\left(36^{\circ} 48^{\prime} 52.9^{\prime \prime} \mathrm{N}\right.$ $\left.121^{\circ} 46^{\prime} 00.9^{\prime \prime} \mathrm{W}\right)$ and the wildlife platform (WILD) ( $\left.36^{\circ} 48^{\prime} 44.2^{\prime \prime} \mathrm{N} 121^{\circ} 46^{\prime} 57.1^{\prime \prime} \mathrm{W}\right)$.

Monterey's public viewing scan sites in blue: otter point (OP) $\left(36^{\circ} 37^{\prime} 55.7^{\prime \prime} \mathrm{N}\right.$ $\left.121^{\circ} 55^{\prime} 20.0^{\prime \prime} \mathrm{W}\right)$, cannery row (CARO) (36 36'40.4”N 121 $\left.{ }^{\circ} 53^{\circ} 47.1^{\prime \prime} \mathrm{W}\right)$, and Hopkins (HOPK) ( $\left.36^{\circ} 37^{\prime} 07.8^{\prime \prime} \mathrm{N} 121^{\circ} 54^{\prime} 05.2^{\prime} \mathrm{W}\right)$. (D) Morro Bay's public viewing scan sites in

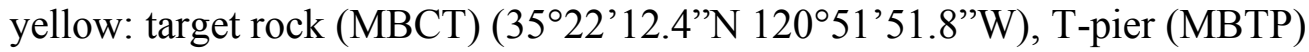

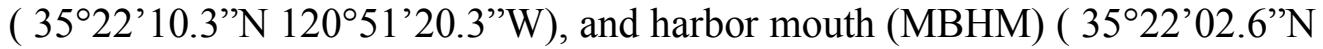
$\left.120^{\circ} 52^{\prime} 01.5 ’ \mathrm{~W}\right)$.

\section{Behavioral Observations}

Behavioral observations were collected by students, interns, and volunteers with the Sea Otter Savvy (SOS) program, using instantaneous scan sampling methods (Altmann, 1974). Scan sampling sessions were conducted from February 2015 to September 2018, approximately three times a week through all seasons, resulting in 652 two-hour scan sessions comprising 1,304 observation hours and $>72,000$ instantaneous observations of sea otter activity states. Observers used high-powered spotting scopes (Eagle Optix Vortex Diamondback 20x to 60x) to scan a predefined (bounded) area every 15 minutes. 
For each detected sea otter group, observers recorded: a) behavior of each otter in the group at the time of the scan; b) occurrence and identity of any potential stimuli within $250 \mathrm{~m}$ of the group, and c) the distance between each potential stimulus and the center of the group. To ensure consistency between observers, potential stimuli were clearly defined and classified (Table 1a) and an ethogram (catalogue of behaviors distinguishing active (a) vs. inactive (i)) was developed (Table 1b). Each behavior in the ethogram was categorized as "active" or "inactive" based on criteria described in Yeates et al. 2007. Scan session shifts were scheduled indiscriminately between the hours of 6:00 am and 6:00 pm, obtaining a representative sample across daylight hours.

Distance (meters) of a potential disturbance stimulus from the sea otter group was determined using range finders (Bushnell Yardage Pro 1000). In most cases, potential stimuli and a sea otter group were parallel (in line) to the viewing station, or the observer could easily shift for a parallel view, allowing stimulus and group distances to be subtracted to acquire the distance between. When potential stimuli and otter were not parallel, compass bearings and distances were recorded for both group and stimulus, and standard triangulation techniques were used to calculate the distance between otters and stimulus. In rare cases where the group was within 30 meters or less of our onshore viewing station, our presence (number of viewers) and distance were included as potential disturbance stimuli.

In addition to behavior and potential disturbance stimuli, we recorded external factors that were expected to influence sea otter behavior: group size, pup presence, kelp canopy, and time of day. For the purposes of this study, a group is defined as either a single otter 
or 2 or more otters within $10 \mathrm{~m}$ of each other. Otters $>10 \mathrm{~m}$ from their nearest neighbor were thus considered a separate group. Pup presence was recorded by assigning a sea otter with a dependent pup code of " $S$ " for small ( $<10$ weeks of age), " $L$ " for large $(>10$ weeks of age), " $P$ " if a pup's age could not be estimated, or " $A$ " for absent (indicating an independent individual). Pup presence was then calculated for analysis as the number of adults with pups divided by the total number of otters in the group (i.e. a value of 0.25 indicates one quarter of the otters in the group have a dependent pup). An index of kelp canopy coverage was estimated based on the proportion of otters in the group within surface kelp canopy (i.e., $0=$ no otters in kelp, $0.5=50 \%$ of otters within kelp, $1=100 \%$ otters within kelp). We also recorded several abiotic variables that may affect sea otter behavior such as wind speed and tide.

Table 1. (A) Potential Disturbance Stimuli with Vessel Size Classification (B) Sea Otter Ethogram

A)

\begin{tabular}{|l|l|l|}
\hline Stimuli Type & \multicolumn{1}{|c|}{ Description } & \multicolumn{1}{c|}{ Classification } \\
\hline CH & $\begin{array}{l}\text { charter Boat, fishing or } \\
\text { sightseeing }\end{array}$ & lgcraft \\
\hline DBC & dive boat, charter & medcraft \\
\hline DBP & dive boat, personal & smcraft \\
\hline FB & fishing boat, not kayak & medcraft \\
\hline HB & hunting Boat & medcraft \\
\hline JS & jet ski & smcraft \\
\hline KR & kayak rentals & smcraft \\
\hline KUR & $\begin{array}{l}\text { rental kayak, unknown } \\
\text { operator }\end{array}$ & smcraft \\
\hline NOI & loud human-caused sound & shore \\
\hline PK & personal kayak & smcraft \\
\hline PS & person on shore or dock & shore \\
\hline ROW & row boat or canoe & smcraft \\
\hline SAL & sailboat, large $>15 \mathrm{ft}$ & lgcraft \\
\hline SAS & sailboat, small $<15 \mathrm{ft}$ & medcraft \\
\hline SC & scuba diver & swim \\
\hline SU & surfer & smcraft \\
\hline SUP & stand up paddleboard & smcraft \\
\hline USGS & USGS research vessel & research \\
\hline WW & whale watching vessel & ecotour \\
\hline
\end{tabular}

B)

\begin{tabular}{|l|l|l|}
\hline Behavior & \multicolumn{1}{|c|}{ Description } & Activity \\
\hline a & resting but alert & i \\
\hline cr & $\begin{array}{l}\text { periscoping, head elevated not } \\
\text { foraging }\end{array}$ & a \\
\hline d & dive & a \\
\hline dt & traveling dive & a \\
\hline e & eating/foraging & a \\
\hline ff & group dives simultaneously & a \\
\hline fgp & female grooming dependent pup & i \\
\hline & $\begin{array}{l}\text { grooming with forward } \\
\text { locomotion }\end{array}$ & \\
gt & hauled out on land & a \\
\hline h & high intensity grooming & a \\
\hline hg & high intensity swimming (wet ) & a \\
\hline hs & interacting & a \\
\hline i & low intensity grooming & i \\
\hline lg & low intensity swimming (dry) & a \\
\hline ls & mounting/copulating & a \\
\hline m & female nursing pup & i \\
\hline n & otter initiating contact w/ person & a \\
\hline op & person initiating contact w/ otter & a \\
\hline po & resting & i \\
\hline r & & \\
\hline
\end{tabular}




\section{Statistical Analysis}

We developed a dynamical model to describe sea otter behavior at sequential time steps, formulated using a hidden Markov model (HMM) framework. In this model, an otter's activity state (active or resting behavior) at time $t$ is treated as a stochastic event, with probabilistic outcomes dependent on its behavior in the previous time step, as well as several time-dependent predictor variables including the presence of and distance to a potential stimulus. We fit this model to the instantaneous scan data using standard Bayesian methods (Gelman et al., 2014) (Appendix 1), implemented using MATLAB and JAGS software (http://mcmc-jags.sourceforge.net).

Process Model. The latent dynamic variable of interest is $A_{i, j, t}$, the probability that otter $i$ at site $j$ is active at time $t$. We treat $A_{i, j, t}$ as a stochastic variable:

$$
\operatorname{logit}\left(A_{i, j, t}\right) \sim \operatorname{Normal}\left(\operatorname{logit}\left(A_{\exp i, j, t}\right), \sigma_{A}\right)
$$

where $A_{\text {exp } i, j, t}$ is the expected activity state for otter $i$ given the set of current conditions and the mean activity state at the previous time step, while the standard error term $\sigma_{A}$ is a fitted parameter representing un-explained variation in activity state. Note that equation 1 uses logit-transformed probabilities for computational tractability. The expected activity probability is calculated as:

$$
\operatorname{logit}\left(A_{\exp i, j, t}\right)=\operatorname{logit}\left(A_{i, j, t-1}\right)+\gamma_{i, j, t} \cdot f_{V}\left(X_{i, j, t}\right)+\gamma_{i, j, t-1} \cdot \rho+f_{C T}\left(A_{i, j, t-1}\right)
$$

where the first term on the right of equation 2 reflects the activity in the previous time step (i.e. in the absence of any other effects, an otter tends to remain in the same activity state); the second term represents the product of a perturbation variable $\left(\gamma_{i, j, t}\right)$ and 
function $f_{V}$, which determines the vulnerability of otter $i$ to perturbation given covariates $X_{i, j, t}$; the third term represents the product of the perturbation variable in the previous time step $\left(\gamma_{i, j, t-1}\right)$ and fitted parameter $\rho$ (which allows for lagged effects of disturbance); and the fourth term on the right of equation 2 is a "centralizing tendency" function, $f_{C T}$, that allows perturbed activity states to eventually return to an "average activity state" $\left(\bar{A}_{j, t}\right)$ specific to the location, time, and set of conditions.

The perturbation variable in equation $2\left(\gamma_{i, j, t}\right)$ depends on a) the presence of one or more potential stimuli at site $j$ and time $t, \mathrm{~b}$ ) the distance between the potential stimuli and the focal otter, and c) a functional relationship between distance and the magnitude of stimulus effects. Specifically, we calculate $\gamma_{i, j, t}$ as:

$$
\gamma_{i, j, t}=\sum_{s}^{s} N_{s, j, t}\left(\left(1 / d_{s, i, j, t}\right)^{\phi_{j}} /\left(1 / d_{\min }\right)^{\phi_{j}}\right)
$$

Where $N_{s, j, t}$ is the number of items of stimulus type $s$ at site $j$ and time $t, d_{s, i j, t}$ is the distance (in meters) between stimuli of type $s$ (if present) and otter $i$, and $d_{\min }$ is a "minimum possible distance", set to $5 \mathrm{~m}$ (this constant serves to normalize equation 3 to a maximum of 1 for a stimulus that is extremely close to an otter). Parameter $\phi_{j}$ (fit separately for each site) determines the functional relationship between the potential impact of a stimulus and distance: larger values of $\phi_{j}$ result in a more rapid decrease in impact with distance. We note that the perturbation variable described by equation 3 represents the potential for disturbance caused by one or more stimuli; however, the 
realized magnitude of impact on activity level also depends on the vulnerability of the focal otter, which is described by vulnerability function $f_{V}$ :

$$
f_{V}\left(X_{i, j, t}\right)=\beta_{0 j}+\beta_{1} \cdot G r p S z_{j, t}+\beta_{2} \cdot \operatorname{Pup}_{i, j, t}+\beta_{3} \cdot \operatorname{Kelp}_{j, t}
$$

where $X_{i, j, t}$ is a vector of covariates for otter $i$ including the number of otters in i's group ( GrpSz), the ratio of pups to adults in the group (Pup) and a binary variable indicating the presence (1) or absence (0) of kelp canopy cover at the groups location (Kelp). The fitted vector of $\beta$ parameters determines how each of these covariates affects the vulnerability of an otter to disturbance.

The centralizing tendency function $\left(f_{C T}\right)$ in equation 2 allows mean activity levels to be "pulled back" towards a context-dependent average value when they are higher or lower than that average, which can occur either because of stochastic variation in activity state (Equation 1) or because of the effects of disturbances in previous time steps (Equation 2). We calculate $f_{C T}$ as:

$$
f_{C T}\left(A_{i, j, t-1}\right)=C \cdot \eta \cdot a b s\left(A_{i, j, t-1}-\bar{A}_{j, t}\right)^{\theta} \quad \begin{aligned}
& \text { if } A_{i, j, t-1} \geq \bar{A}_{j, t}, C=-1 \\
& \text { if } A_{i, j, t-1}<\bar{A}_{j, t}, C=1
\end{aligned}
$$

where $C$ is a switch variable which determines sign of the function (depending on whether the current activity level is above or below the expected average) and $\eta$ and $\theta$ are fitted parameters which together determine the strength and functional form of the centralizing tendency. We note that the inclusion of a centralizing tendency function in our model reflects both biological reality and mathematical necessity, otherwise stochasticity would eventually result in the drift of average activity state towards an absorbing boundary (100\% active or 100\% inactive), and/or any effects of disturbance (in 
terms of increased activity levels) would be permanent. By fitting the parameters for equation 5 we allow for either weak/slow or strong/fast tendencies to return to average activity levels, as determined by observed data. The average activity state for site $j$ at time $t\left(\bar{A}_{j, t}\right)$ is calculated as:

$$
\operatorname{logit}\left(\bar{A}_{j, t}\right)=\alpha_{0, j}+\alpha_{1} \cdot G r p S z_{j, t}+\alpha_{2} \cdot P u p_{j, t}+\alpha_{3} \cdot \operatorname{Kelp}_{j, t}+\alpha_{4} \cdot P M 1_{t}+\alpha_{5} \cdot P M 2_{t}
$$

where the first three covariates are identical to those described in equation 4 , while the time of day covariates $P M 1$ and $P M 2$ are binary switch variables that allow for differences in activity in the early afternoon $(P M 1=1$ for $12: 00<t<15: 00)$ and late afternoon $(P M 2=1$ for 15:00<t<18:00) as compared to morning $(P M 1=P M 2=0)$. The fitted vector of $\alpha$ parameters determines how each of these covariates affects average activity state.

Observation Model. The observed data used to fit the model consist of the recorded behavioral state $(B)$ of each otter $(i)$ in each scan ( $t$, corresponding to a single scan) at each site $(j)$, recorded as a binary response variable scored as 1 for active and 0 for inactive behavior. Each observed data point is treated as a Bernoulli trial, with probability of success determined by $A_{i, j, t}$ :

$$
B_{i, j, t} \sim \operatorname{Bernoulli}\left(\operatorname{Prob}=A_{i, j, t}\right)
$$

Prior Model. We use vague priors for all model parameters, thereby allowing the data to have maximal influence on posterior distributions. For all logit function parameters $(\alpha, \beta$ and $\rho)$ we use Cauchy priors (Gelman, Jakulin, \& Grazia, 2008) with location parameter $=0$ and scale parameter $=2.5$. For variance parameter $\sigma_{A}$ we use a 
Half-Cauchy prior (Gelman, 2006) with location parameter $=0$ and scale parameter $=$ 2.5, and we use the same Half-Cauchy priors for parameters $\eta, \theta$ and $\phi$ as they are mathematically constrained to be positive.

Summarizing Model Results. We report means and 95\% credible intervals (CI) for all estimates of model parameters. To simplify interpretation of results, we also define a derived statistic called "relative disturbance effect" (RDE), which represents the actual increase in activity probability for an activity associated with the presence of a given stimuli (at a specified distance and set of covariate values) relative to the corresponding probability of activity in the absence of that stimulus. $\mathrm{RDE}$ is calculated by solving equation 2 both with and without a stimulus present, then subtracting the latter from the former. To standardize comparisons of RDE we define a "standard stimulus" as a single kayak at a distance of $10 \mathrm{~m}$, and we define standard covariate values as GrpSz $=10$, Pup $=$ 0.5, Kelp $=0.5$, time of day $=$ morning, and previous activity state $\left(A_{i j, t,-1}\right)=0.5$. We compare RDE between study locations and study sites, and we evaluate the effects of covariates by comparing RDE values under differing values of each covariate $(\mathrm{GrpSz}=$ 20 vs, 1, Pup $=1$ vs. 0, Kelp $=1$ vs. 0 , time of day $=$ PM1/PM2 vs. morning) while holding all other covariates fixed at their standardized values (we use Monterey as the default location for covariate comparisons).

Recognizing that otters that are resting are more susceptible to disturbance (i.e. an already-active otter cannot be disturbed, by definition) we also evaluated the effect of covariates on mean expected activity state, to assess which sets of conditions were more associated with resting behavior and thus greater potential for disturbance. Comparisons 
of covariate effects were made holding all other covariates fixed at the standardized values described above. For all RDE and mean expected activity state comparisons we provide means and $95 \% \mathrm{CI}$ as calculated from the joint posterior distribution of the derived statistic (i.e. each parameter combining to the calculations is sampled from its posterior distribution) (Appendix 2, 3).

To evaluate and compare the effect of stimulus distance on the potential for disturbance (PD), we plot variable $\gamma$ as a function of distance between a stimulus and an otter, using a single kayak as the standard stimulus, and we compare PD curves to assess how the disturbance distance relationship varies across study locations. We note that PD represents a unitless index of the relative potential for disturbance, which varies from 1 (at $d_{\min }$ ) to values approaching 0 at very large distances, with the shape of the function providing insights into "safe" distances where the magnitude of potential disturbance is acceptably low. The advantage of using PD for these comparisons is that it is context independent, measuring the relative potential for disturbance irrespective of covariate values. We calculate the distances associated with $\mathrm{PD}$ values of $0.05,0.1,0.2,0.3$ for each study location (Appendix 4).

Calculating Energetic Costs. We estimated the energetic costs of disturbance by calculating the metabolic expenditures associated with the increased time spent in active behavior due to a typical disturbance scenario, relative to "normal" behavior of the same otter in the absence of that disturbance. We calculated behavior-specific metabolic costs for male sea otters using the published value for average swimming metabolic rate $(0.59$ $\mathrm{kJ} \mathrm{min}{ }^{-1} \mathrm{~kg}^{-1} \pm 0.03$ ) for active behavioral states and the published value for average 
resting metabolic rate $\left(0.27 \mathrm{~kJ} \mathrm{~min}^{-1} \mathrm{~kg}^{-1} \pm 0.02\right)$ for inactive behavioral states (Yeates et al., 2007). We selected average swimming metabolic rate to represent the active state because this was the most common avoidance behavior, and because there is little difference in metabolic rate between the different activities previously measured (swimming, grooming, and feeding) (Yeates et al., 2007). In the case of independent females (no dependent pup), activity-specific metabolic rates were converted from published VO2 values (Thometz et al., 2014; Williams, 1989) using standard conversion factors ( $\left.1 \mathrm{mlO} 2 \mathrm{~min}^{-1} \mathrm{~kg}^{-1}=0.02 \mathrm{~kJ} \mathrm{~min}^{-1} \mathrm{~kg}^{-1}\right)$ (Yeates et al., 2007). The average swimming rate $\left(0.59 \mathrm{~kJ} \mathrm{~min}^{-1} \mathrm{~kg}^{-1} \pm 0.03\right)$ was used to represent the active behavioral state and average resting metabolic rate $\left(0.27 \mathrm{~kJ} \mathrm{~min}^{-1} \mathrm{~kg}^{-1} \pm 0.04\right)$ were used to represent the inactive behavioral state (Thometz et al., 2014; Williams, 1989). The published metabolic standard deviations were incorporated into the disturbance simulations to account for uncertainty in the metabolic rates, and all metabolic values were re-scaled to correspond to the 15-minute time step interval of the instantaneous scan data. We calculated metabolic expenditures and net cost of disturbance as:

\section{Field Metabolic Rates (FMR).}

$$
\begin{aligned}
& F M R^{0} \text { (baseline) } \\
& =\left[P_{t} \cdot \text { metabolic rate (active) }+\left(1-P_{t}\right) \cdot \text { metabolic rate (inactive) }\right] \cdot 15 \text { min }
\end{aligned}
$$

$$
\begin{aligned}
& \text { FMR }{ }^{I}(\text { with disturbance) } \\
& \left.=\left[P^{\prime} \cdot{ }_{t} \cdot \text { metabolic rate }(\text { active })+\left(1-P_{t}^{\prime}\right) \cdot \text { metabolic rate (inactive }\right)\right] \cdot 15 \text { min }
\end{aligned}
$$




\section{Net Cost of Disturbance.}

$$
\text { Cost }=F M R^{1} \text { (with disturbance) }-F M R^{0} \text { (baseline) }
$$

where $P_{t}$ is the baseline probability of activity and $P_{t}^{\prime}$ is the probability in the presence of the specified disturbance stimulus. $F M R^{0}$ represents metabolic expenditures associated with baseline activity and $F M R^{I}$ represents metabolic expenditures in the presence of a given disturbance stimuli. Cost therefore represents the net cost of a given disturbance simulation, the difference between $F M R^{1}$ and $F M R^{0}$.

To account for stochastic variation in sea otter activity, behavioral responses and consequent energetic costs from daily disturbance, we simulated 1000 iterations of each disturbance scenario. For each simulation, mean activity levels and behavioral dynamics were generated using equations 1-6, both with and without a specified disturbance, and then activity levels were converted to energetic costs using equations $8-10$. We report the mean and variation of increased activity and consequent energetic costs $(\mathrm{kJ})$ for one 12hour day (6AM-6PM). The standard disturbance scenario used for these simulations was one small craft (i.e. kayak) at $\leq 20 \mathrm{~m}$ (critical distance representing 5 kayak lengths: current recommended distance) occurring six times through the day (the overall average disturbance frequency) in Monterey (default location). Covariate values were held constant with GrpSz $=10$, Pup $=0.5$, Kelp $=0.5$. Additional simulations were run for all three locations at varying distances and disturbance frequencies to provide energetic cost tables. Average values of all energetic costs and 95\% CI are reported (Appendix 5).

We used $27.7 \mathrm{~kg}$ to represent the average mass of a male sea otter (Yeates et al., 2007), and $19.89 \mathrm{~kg}$ for an average female sea otter (Williams, 1989). The conversion 
from $\mathrm{kJ}$ to $\mathrm{kcal}(1 \mathrm{~kJ}=0.239 \mathrm{kcal})$ along with the average energy for specific prey species (Oftedal, Ralls, Tinker, \& Green, 2007), allowed us to explore the number of a prey required to compensate for the energetic cost due to the disturbance using the following equation:

number of prey = energetic cost (kcal) / average energy of prey species (kcal) 


\section{Results}

\section{Disturbance Effects}

The RDE was similar across sites and locations and showed high among-site and within-site variability. Site MBCT had the lowest average RDE (Figure 2: $0.041,95 \% \mathrm{CI}$ (0.081, 0.005)), while sites SEBE, WILD and MBHM exhibit highly variable effects, with average values not significantly distinguishable from 0 (Figure 2: SEBE: $0.180,95 \%$ CI (0.336, -0.017); WILD: 0.164, 95\% CI (0.334, -0.090); MBHM: 0.115, 95\% CI $(0.298,-0.032))$. JTTY and CARO showed higher disturbance effects, significantly greater than MBCT (Figure 2: JTTY: 0.268, 95\% CI (0.350, 0.178); CARO: 0.231, 95\% CI $(0.328,0.121))$.

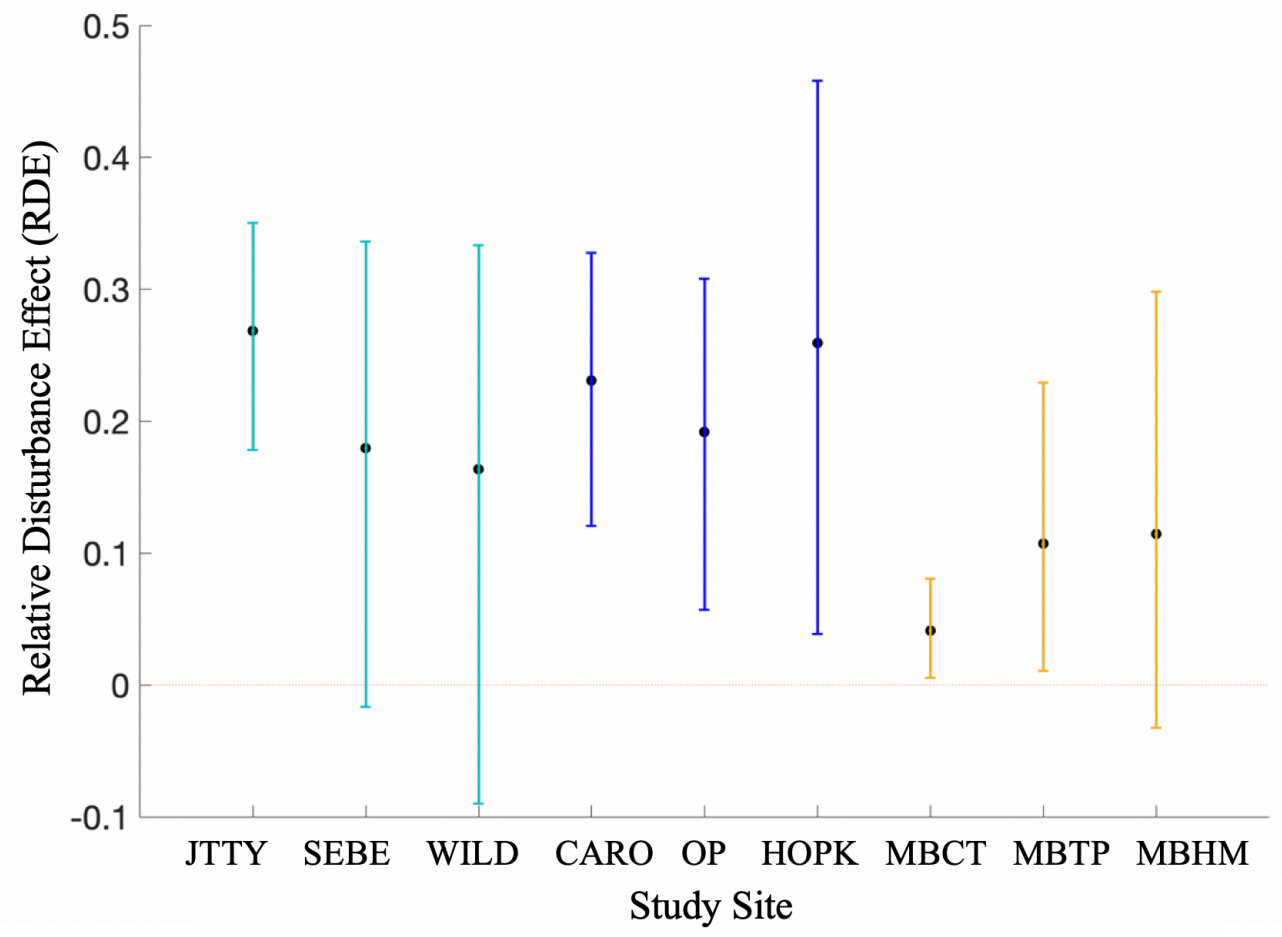

Figure 2. Relative Disturbance Effect (indicator of sea otter sensitivity to disturbance) across study sites given: group size $=10$, pup ratio $=0.5$, kelp canopy $=0.5$, time of day $=$ morning, previous activity state $\left(A_{i, j, t-1}\right)=0.5$, and small craft stimulus. Morro Bay target 
rock (MBCT) has lowest $\mathrm{RDE}$ at $0.041,95 \% \mathrm{CI}(0.081,0.005)$. Moss Landing sites (turquoise): JTTY, SEBE, WILD; Monterey sites (blue): CARO, OP, HOPK; Morro Bay sites (yellow): MBCT, MBTP, MBHM.

When grouped by location, Moss Landing and Monterey RDE values were similar, indicating sea otters exhibit comparable sensitivity to disturbance at these two locations after accounting for site-level differences (Figure 3: Moss Landing: 0.204, 95\% CI $(0.332,0.048)$; Monterey: $0.220,95 \%$ CI $(0.353,0.070))$. Morro Bay showed a slightly lower average $\mathrm{RDE}$, indicating that sea otters in Morro Bay may experience reduced effects of disturbance (Figure 3: Morro Bay: 0.099, 95\% CI $(0.218,0.001)$ ).

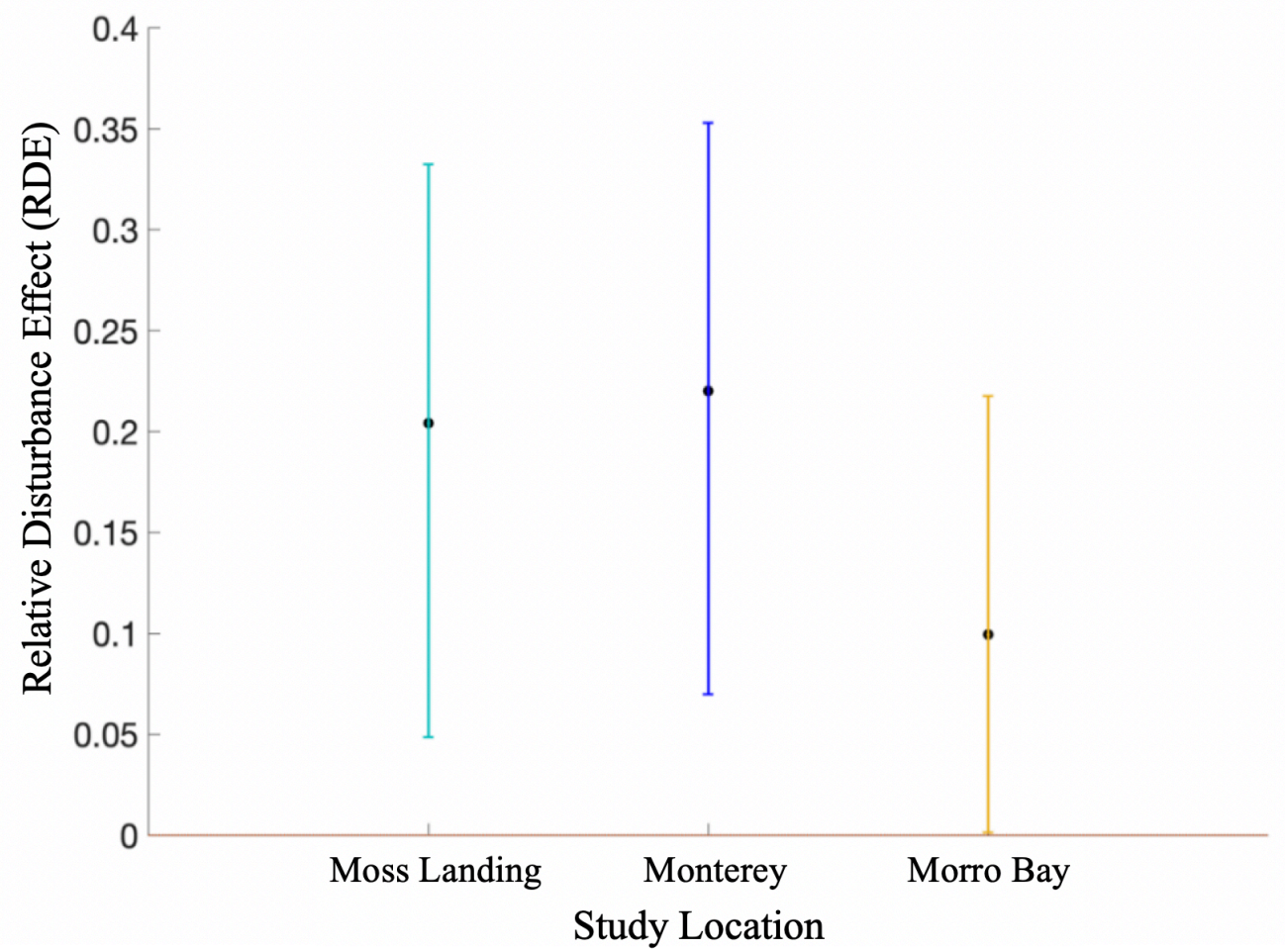

Figure 3. Relative Disturbance Effect (indicator of sea otter sensitivity to disturbance) across study locations (Moss Landing (light blue); Monterey (blue); Morro Bay (yellow) given: group size $=10$, pup ratio $=0.5$, kelp canopy $=0.5$, time of day $=$ morning, previous activity state $\left(A_{i, j, t-1}\right)=0.5$, and small craft stimulus. Morro Bay has the lowest average Relative disturbance effect at $0.099,95 \%$ CI $(0.218,0.001)$. 
Comparisons of RDE across covariate levels indicated little effect of covariates on mean disturbance effects. Differences in GrpSz, Pup and time of day showed no apparent effect on RDE (Figure 4), while the presence of Kelp was associated with a slight increase in RDE (Figure 4: Kelp $=1$ : 0.259, 95\% CI (0.356, 0.155); Kelp $=0: 0.176,95 \%$ CI $(0.316,0.025))$. We note that the RDE statistics are standardized by assuming a constant initial activity state; however, an otter's vulnerability to disturbance also depends on its activity level prior to a disturbance stimulus. This is because resting otters are subject to disturbance while active otters are not, so all else being equal there will be a greater risk of disturbance for groups having a lower mean activity state. Thus, covariates may affect vulnerability to disturbance via their effects on RDE, or via their effects on mean expected activity state. There were significant differences in Mean Expected Activity Level associated with differences in GrpSz and Kelp (Figure 5, Appendix 2). Increasing GrpSz from 1 to 20 is associated with a significant decrease in sea otter activity level (Figure 5: GrpSz $=1: 0.276,95 \%$ CI $(0.376,0.189)$; $\operatorname{GrpSz}=20$ : $0.10595 \% \mathrm{CI}(0.157,0.065))$, as is the presence of Kelp (Figure 5: Kelp $=0: 0.328,95 \%$ CI $(0.448,0.227) ;$ Kelp $=1: 0.08895 \%$ CI $(0.131,0.055))$. There were also small but non-significant differences in mean expected activity state associated with Pup and time of day (Figure 5). 

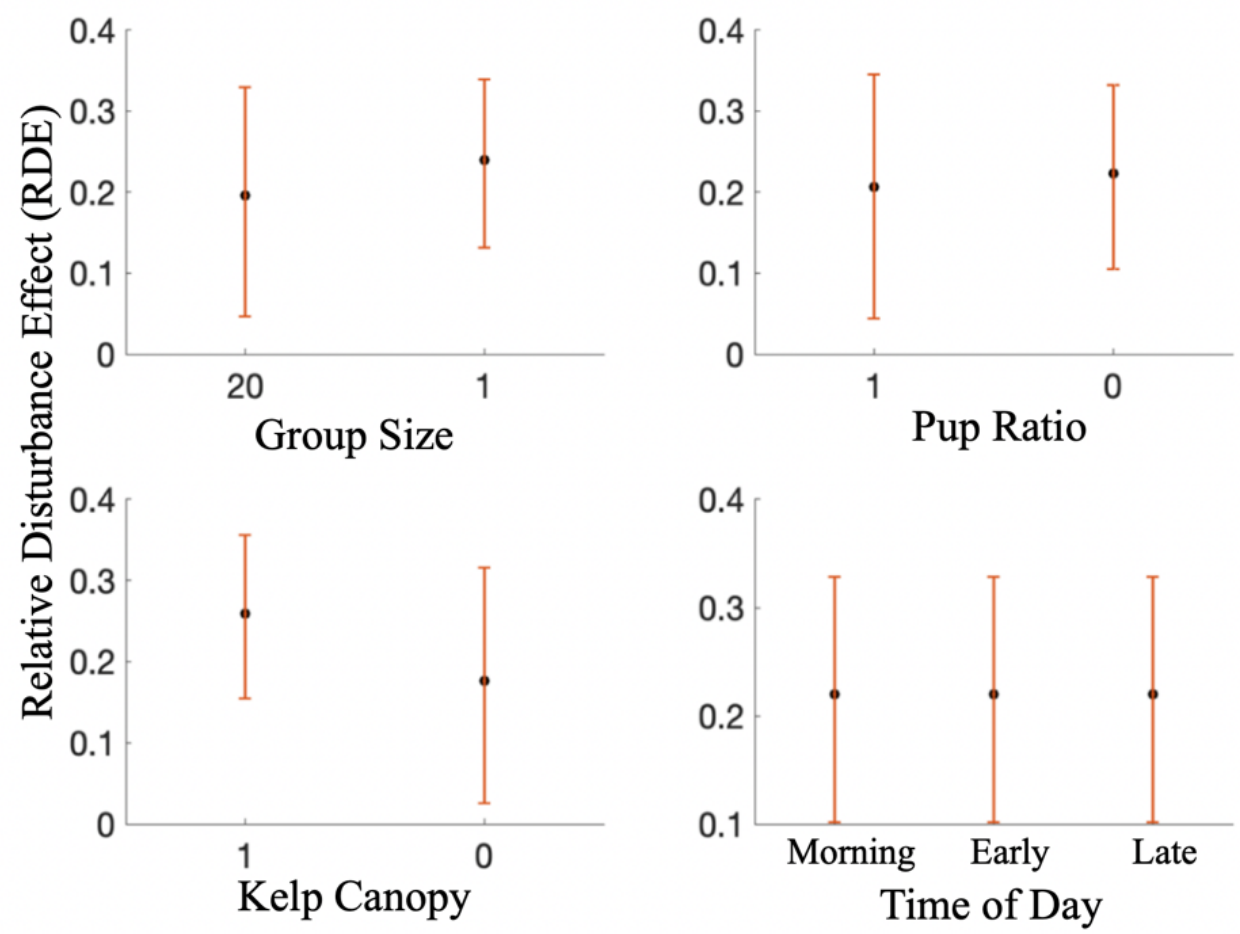

Figure 4. Covariate effects are compared using Relative Disturbance Effect (indicator of sea otter sensitivity to disturbance) and differing values of each covariate (group size $=$ 20 vs, 1 , pup ratio $=1$ vs. 0 , kelp canopy $=1$ vs. 0 , time of day $=$ morning vs. early afternoon vs. late afternoon) while holding all other covariates fixed at their standardized values (group size $=10$, pup ratio $=0.5$, kelp canopy $=0.5$, time of day $=$ morning, previous activity state $\left(A_{i, j, t-1}\right)=0.5$, and small craft stimulus). Monterey is the default location for covariate comparisons. 

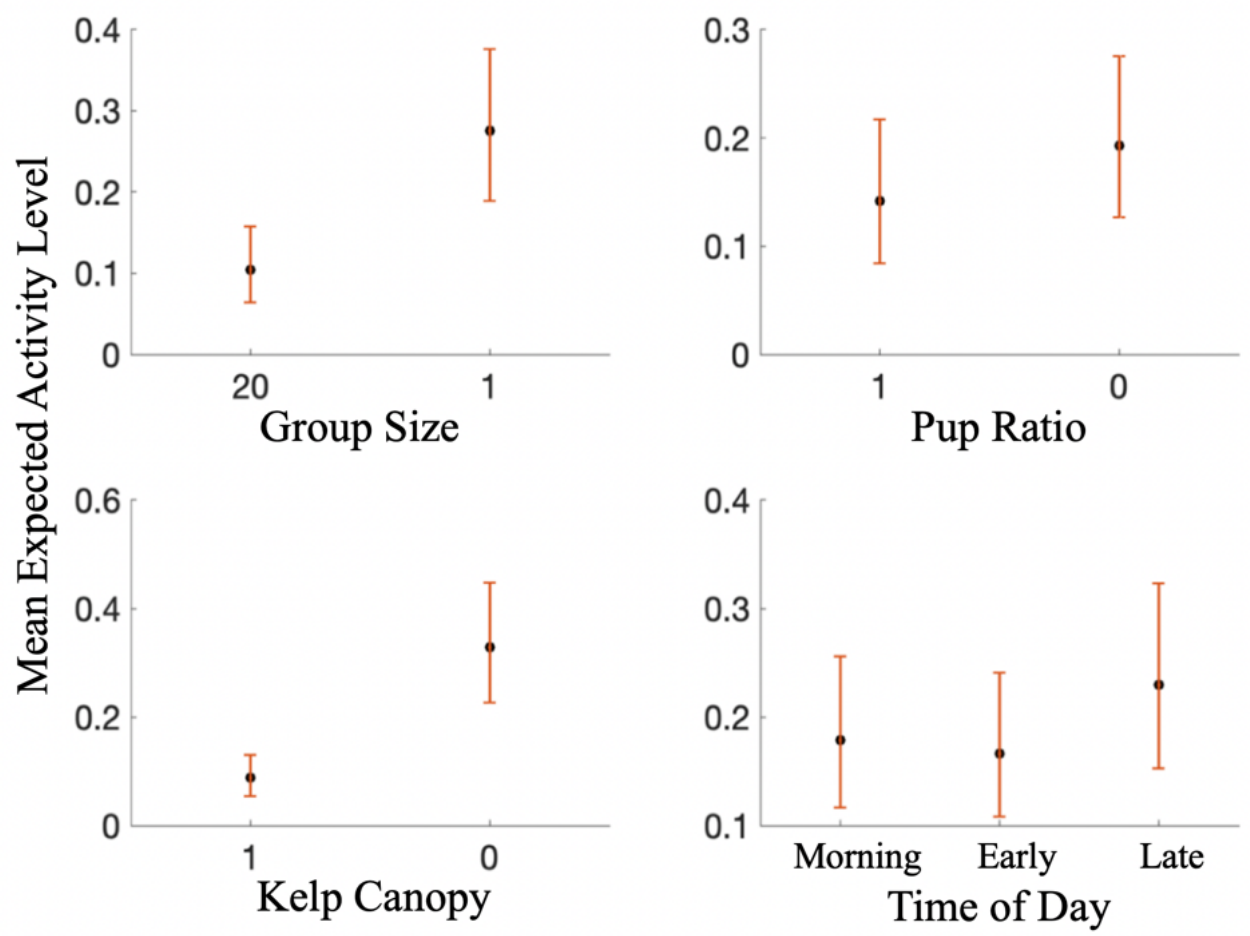

Figure 5. Mean expected activity level for sea otters is evaluated across covariates to assess which sets of conditions were more associated with resting behavior and thus greater potential for disturbance. Comparisons of covariate effects were made holding all other covariates fixed at the standardized values (group size $=20 \mathrm{vs}, 1$, pup ratio $=1 \mathrm{vs}$. 0 , kelp canopy $=1$ vs. 0 , time of day $=$ morning vs. early afternoon vs. late afternoon, previous activity state $\left.\left(A_{i, j, t-1}\right)=0.5\right)$.

\section{Distance Effects}

As hypothesized, the PD (potential disturbance effect) increased as the distance between the stimulus and otter group decreased. The nature of the functional relationship between PD and distance differed between locations, with Morro Bay showing lower PD at a given distance as compared to the other locations (Figure 6). For example, a kayak approaching to within $17 \mathrm{~m}$ of a group in Morro Bay has an equivalent PD as a kayak approaching to within $34 \mathrm{~m}$ of a group in Moss Landing or $48 \mathrm{~m}$ in Monterey (Appendix 4). If the goal were to reduce the potential for disturbance to $10 \%$ of its maximum value 
$(\mathrm{PD}=0.1)$, then an appropriate minimum allowable distance for all locations would be 54m (Appendix 4).

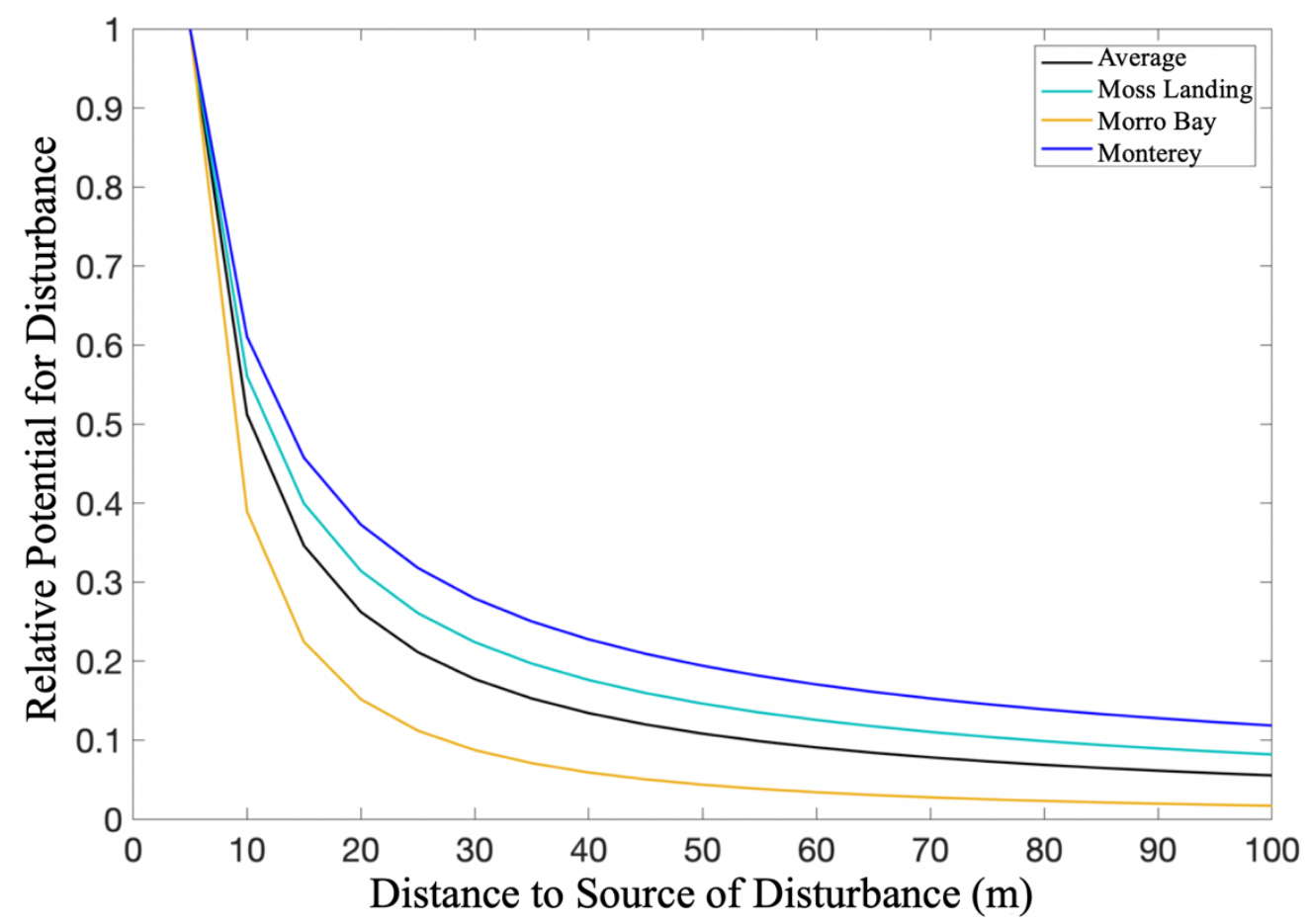

Figure 6. The Relative Potential Disturbance Effect (PD) for sea otters at varying distances given different locations: Moss Landing (turquoise), Monterey (blue), Morro Bay (yellow), Average (black).

\section{Energetic Costs}

A typical simulation of 6 small craft disturbances in Monterey at $20 \mathrm{~m}$ or closer shows spikes in the probability that a sea otter will become active, as compared to a baseline "no-disturbance" scenario (Figure 7a). The residual behavioral effects of each disturbance are persistent but decline over time. Coupling metabolic rates to this simulation reveals similar spikes of increased metabolic expenditures for a $27.7 \mathrm{~kg}$ male 
sea otter (Figure 7b), with 6 disturbances at $20 \mathrm{~m}$ resulting in an average net daily cost of $210.1 \mathrm{~kJ} \pm 80.76$ (Figure 8, Appendix 5).

A)

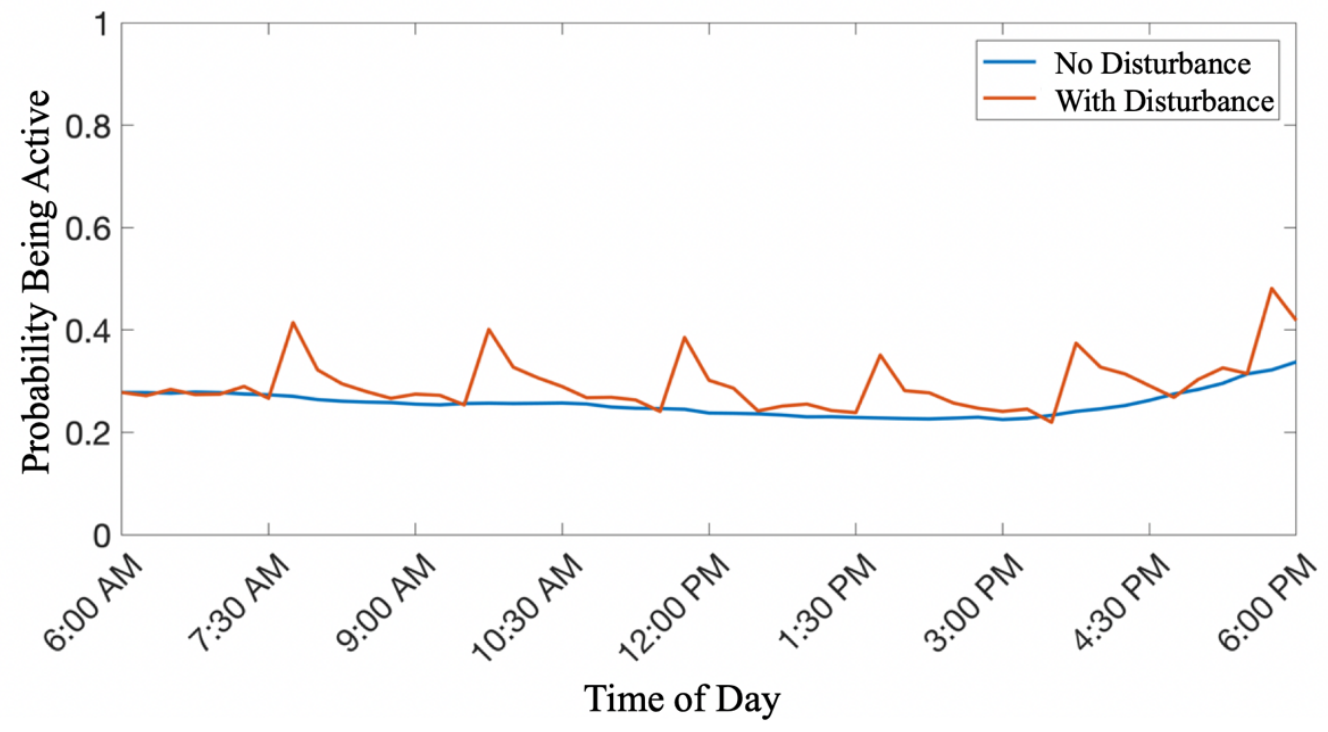

B)

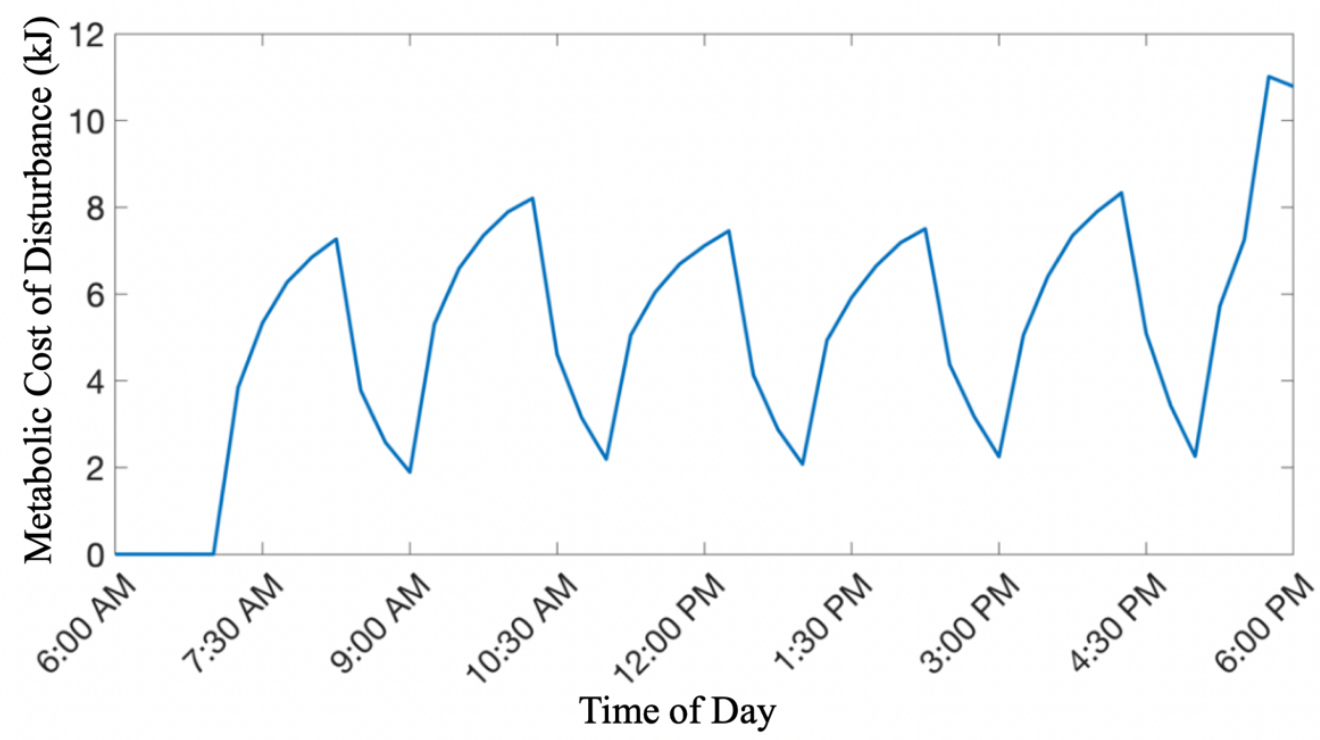

Figure 7. (A) The probability of a sea otter being active with six disturbances (small craft stimulus) with a $20 \mathrm{~m}$ critical distance. (B) The metabolic cost of disturbance $(210.1 \mathrm{~kJ} 95 \% \mathrm{CI}(215.11,205.1))$ for a single $27.7 \mathrm{~kg}$ male sea otter in $\mathrm{kJ}$ across twelvehour period (daylight hours) for a small craft at $\leq 20 \mathrm{~m}$ distance. 
Averaged over multiple simulations at Monterey, to account for stochasticity in both behavior and timing of the 6 disturbances, the average daily energetic costs show substantial variation and a decreasing trend with distance (Figure 8, Appendix 5). At a $15 \mathrm{~m}$ critical distance the six disturbances would cost $249.04 \mathrm{~kJ} \pm 97.16$ for an average $27.7 \mathrm{~kg}$ male sea otter, while the same number of small craft disturbances would be $122.87 \mathrm{~kJ} \pm 49.98$ at $50 \mathrm{~m}$ (Appendix 5).

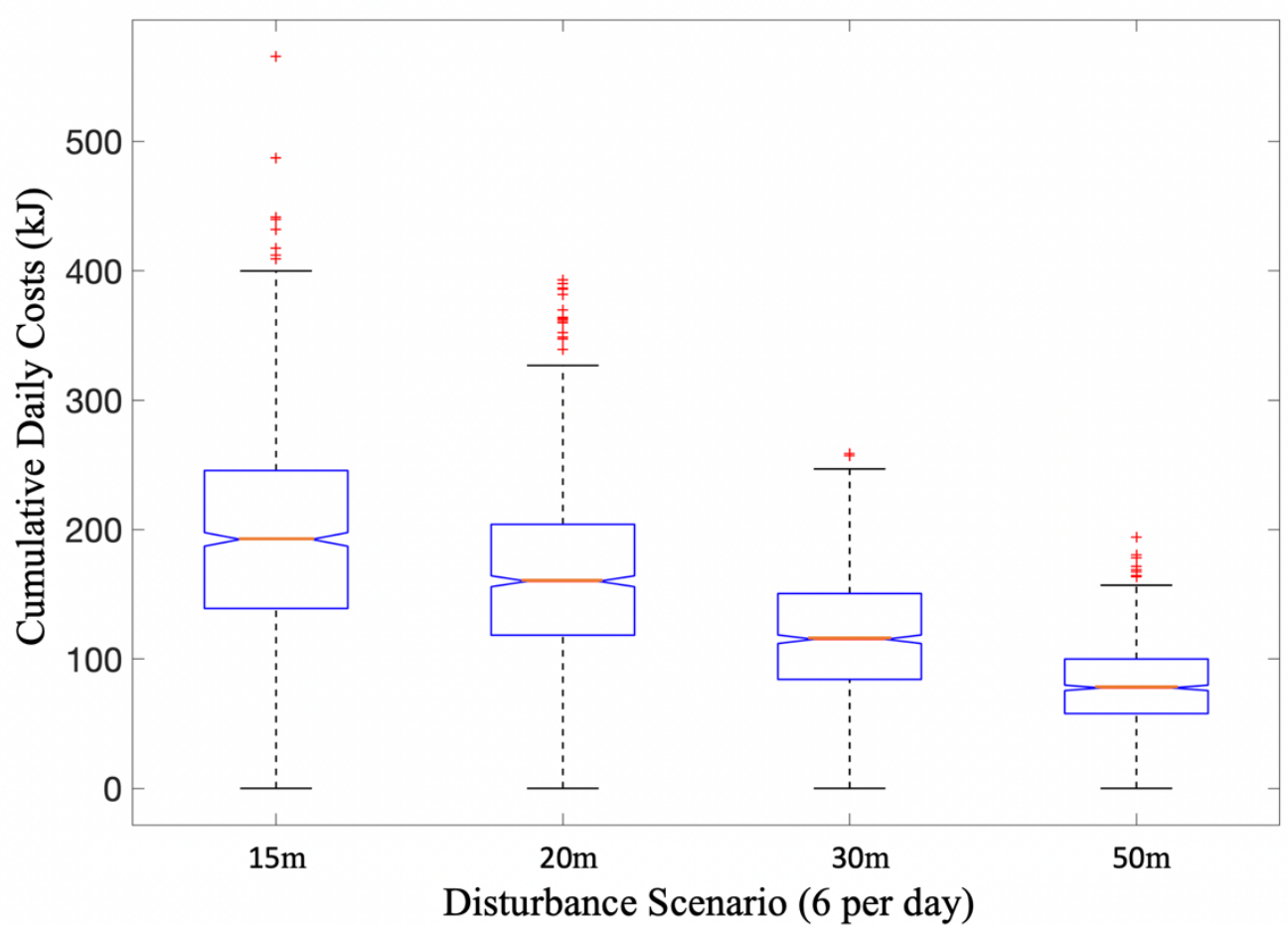

Figure 8. The cumulative energetic cost (kJ) for a $27.7 \mathrm{~kg}$ male sea otter in Monterey given six disturbances of a stimulus (small craft) at $15 \mathrm{~m}, 20 \mathrm{~m}, 30 \mathrm{~m}$, and $50 \mathrm{~m}$ critical distances. The median (middle quartile) for each simulation is the midline in orange with the box representing the interquartile range (the middle $50 \%$ of values). The whiskers display the values outside the middle $50 \%$. Notches are the $95 \%$ confidence intervals of the median, and outliers are represented by the red plus.

By exploring small craft disturbance scenarios across locations, we found that otters at Monterey and Moss Landing experience similar energetic costs of disturbance, while 
otters at Morro Bay experience lower energetic costs under an equivalent disturbance scenario (Figure 9, Appendix 5). For example, the average daily energetic cost for a 27.7 $\mathrm{kg}$ male sea otter given a disturbance at $15 \mathrm{~m}$ shows a significant difference $(163.03 \mathrm{~kJ})$ between Monterey (249.04 kJ \pm 97.16) and Morro Bay (86.01 kJ \pm 37.11$)$ (Figure 9). In general, the energetic costs of disturbance increase as critical distances decrease and as disturbance frequency increases (Appendix 5). Similar trends are observed for independent females, although an average female experiences lower absolute costs $(\mathrm{kJ})$ as compared to an average male due to their lower mass (Figure 9, Appendix 5).
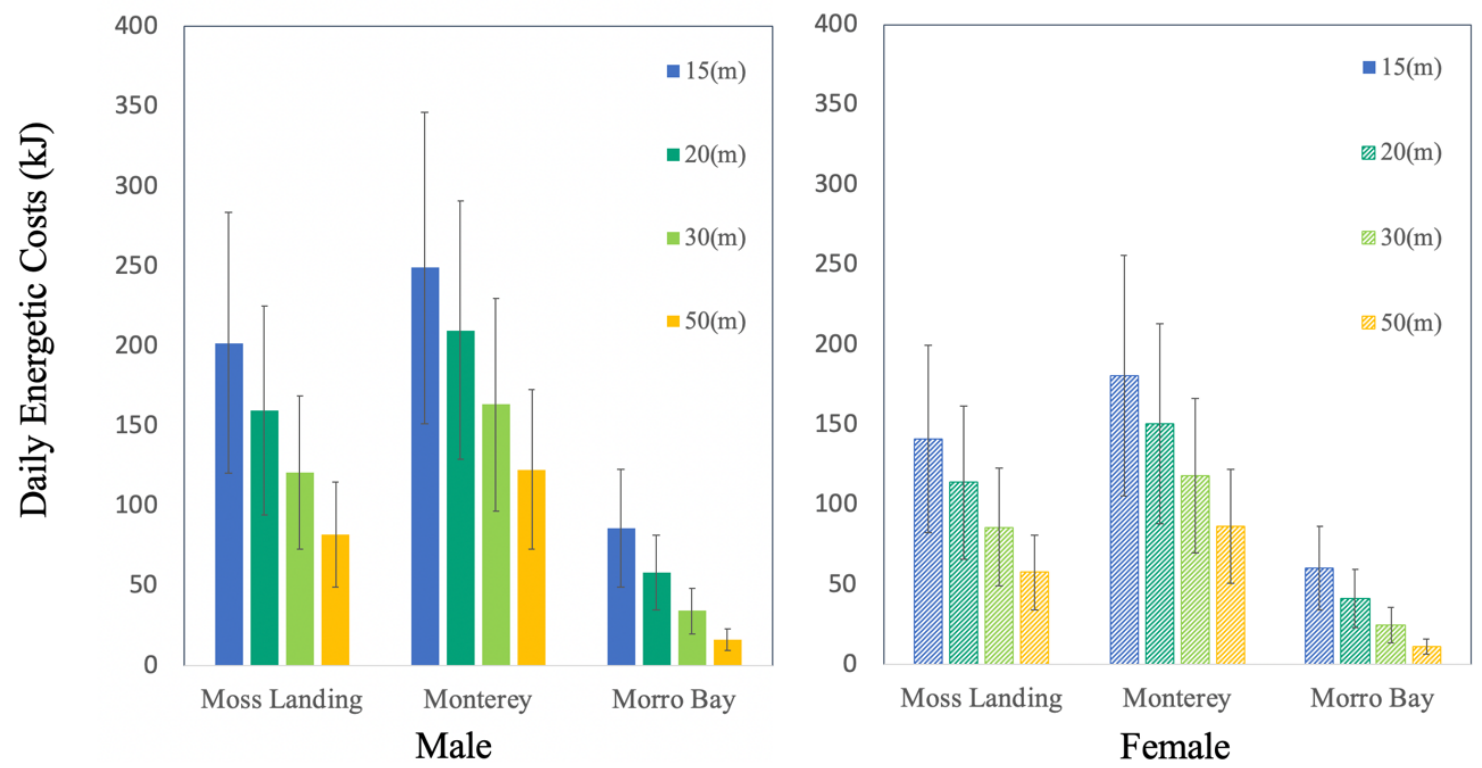

Figure 9. The average energetic cost $(\mathrm{kJ}) \pm \mathrm{SD}$ for an average male $27.7 \mathrm{~kg}$ sea otter (filled) and an average female $19.89 \mathrm{~kg}$ sea otter (textured), given six disturbances (small craft) across locations and varying critical distances: $15 \mathrm{~m}$ (blue), $20 \mathrm{~m}$ (green), $30 \mathrm{~m}$ (lime), $50 \mathrm{~m}$ (yellow).

Assuming a critical distance of $20 \mathrm{~m}$ and 6 disturbances per day in Monterey, the increase in daily prey consumption needed to account for the additional energetic costs 
for a typical male correspond to an extra third of a Dungeness crab (Metacarcinus magister), 11 pacific littleneck clams (Leukoma staminea) or 20 snails (Tegula montereyi) (Oftedal et al., 2007) (Appendix 6). Given that an average male would consume approximately a quarter of his mass $(6.92 \mathrm{~kg})$ in prey per day, this estimated cost from disturbance represents $<1 \%$ of the daily food requirement. 


\section{Discussion}

Disturbance from ecotourism has an effect on sea otter behavior and associated energetic costs. Though the associated energetic costs for one day may appear relatively minor compared to daily food requirements, these daily values will add up to substantial costs over weeks, months and years, which could have significant implications for an already energy-stressed animal. Moreover, these calculations do not account for latent foraging costs, assimilation efficiency, and cumulative energetic demands, which should be considered in future studies. We found that the magnitude of human disturbance effects varies by site, location, and distance. We also found that mean activity levels (which mediate realized vulnerability to disturbance, since based on the design of this project only resting animals can be disturbed) were affected by several covariates, including group size and kelp canopy cover.

\section{Variation in Disturbance Effects}

To evaluate the effects of disturbance and how covariates (location/site, group size, pup ratio, kelp canopy, time of day) influence these effects, we explored the proportional increase in sea otter activity associated with a disturbance (Relative Disturbance Effect or $\mathrm{RDE}$ ) and also the effect of those covariates on the mean expected activity level prior to a disturbance. The magnitude of RDE was similar across locations, suggesting similar behavioral responses, although Morro Bay showed a slightly lower RDE (Figure 3). However, when compared at the site level, Moss Landing's JTTY and Monterey's CARO sites had significantly higher average RDE values than Morro Bay's MBCT site, while the remaining sites displayed lower or in some cases no disturbance effect (Figure 2). 
This may be because the JTTY, CARO, and MBCT were sites with consistent sea otter groups for behavioral scans and represent a majority of the data collected, but they also represent the sites with higher boat-based tourist traffic.

Interestingly, the non-spatial covariates we considered showed no significant effects on $\mathrm{RDE}$, although there was a trend towards increased $\mathrm{RDE}$ associated with the presence of kelp (Figure 4). However, there were significant covariate effects on mean expected activity level, which itself mediates the potential vulnerability to disturbance (i.e. groups having a lower mean activity level - more otters resting - will show a greater response to a given disturbance stimulus, since only resting otters can be disturbed). For example, given a potential disturbance stimulus with associated effect size of 0.2 (a $20 \%$ probability of disturbing a resting otter) and a group of 100 animals, if the mean activity state was 0.2 we would expect (on average) 16 animals to be disturbed (Appendix 7). However, if the mean activity state was 0.8 then only 4 animals (on average) would be disturbed, based on simple binomial probability outcomes (Appendix 7). We found that otters were significantly more likely to be inactive when in kelp canopy (Figure 5), consistent with previous reports (Riedman \& Estes, 1990). Similarly, while group size had minimal effects on RDE, it had strong effects on activity state: otters within a group of 20 were 3 times more likely to be resting than when they were not in a group (Figure 5), and thus more vulnerable to potential disturbance.

In contrast to our expectations, pup ratio did not significantly affect RDE (Figure 4) and had only slight effects on mean activity state (females with pups were more likely to be inactive; Figure 5). This lack of any significant effect of pup presence is perhaps a 
result of how pups were recorded (females with pups were not followed continuously between scans). Based on observation notes during behavioral scans, reproductive females appeared to resist becoming active in the presence of a disturbance stimulus at specific locations. The costs of disturbance for females with pups may be greater than for females without pups, including the additional costs of moving, grooming, and nursing. Thus, it is possible females may try harder to avoid changes in activity state.

Furthermore, the additional energetic costs of lactation mean that females are strongly selected to minimize costs (and thus maximize resting time) post-parturition (Chinn et al., 2016; Thometz et al., 2014). Given how pup presence was recorded and analyzed, a future study would benefit from directed focal follows of reproductive females to better explore the effect of pup presence.

\section{Distance Effects}

The frequency and degree of sea otter response and consequent energetic cost due to a disturbance depends on distance between the otter and the disturbance stimuli. Our analyses clearly support the prediction that the closer a stimulus is to a sea otter, the greater probability of a potential disturbance (Figure 6), and also allow us to quantify this relationship. We can use this information to determine safe approach distances that will minimize costs of human disturbance. Our example, using the average PD of 0.1 (10\% of maximum potential disturbance) suggests a safe distance of $54 \mathrm{~m}$ (Appendix 4), a similar distance to the National Oceanic and Atmospheric Association viewing guidelines for resting pinnipeds (https://www.westcoast.fisheries.noaa.gov). 
When analyzing PD across locations, it is clear that a sea otter's location influences how the individual reacts to stimuli. Sea otters in Morro Bay do not show the same response to a stimulus as Monterey and Moss Landing, despite all locations having nearly constant exposure to many forms of anthropogenic stimuli (Figure 6). It is possible that the difference in geography and or group composition of sea otters in Morro Bay may be contributing to this difference. It is also possible that Morro Bay otters are habituated to disturbance, in which case it is perhaps not surprising that they would show less response (at a given distance) than otters at Monterey and Moss Landing. However, behavioral habituation by wildlife is extremely difficult to establish, and clearly observable differences (e.g. diminished response to disturbance) can be misleading (Bejder et al., 2009). Though many studies use the measurement of tolerance, and how this relates to disturbance intensity, it has been argued that habituation research requires long-term sequential measurements of individual responses (Bejder, Samuels, Whitehead, \& Gales, 2006; Nisbet, 2000). Our data do measure individual responses, but to fully explore habituation it will be necessary to further explore more subtle behaviors that may indicate disturbance effects without obvious changes in activity state.

Our research focused on the visible change in activity and the corresponding energy lost. Even if a sea otter was alert and aware of an approaching disturbance stimulus, it was still categorized as inactive. We note that sea otters resistant to activity change, but alert, could experience hidden costs such as stress hormones and increased heart rate that are not visible but have long-term negative impacts on a population (Dantzer et al., 2014; 
Hill et al., 2004). Our results therefore suggest a need for further research on sea otter habituation to disturbance and the resulting physiological effects.

\section{Energetic Cost of Disturbance}

The coupling of metabolic rates to sea otter activity levels allows us to quantify for the first time the energetic costs of disturbance (Figure 7b). Our empirically-informed dynamic model allows us to conduct realistic simulations that provide meaningful estimates of energetic costs for a given scenario. We can also make these costs more tangible by expressing them in terms of the associated dietary requirements (Oftedal et al., 2007). Typical disturbance regimes result in increased prey requirements for individual sea otters, although the number of additional prey items required varies by prey taxa. Sea otters in central California tend to be dietary specialists (Tinker, Bentall, \& Estes, 2008), and thus different sea otters will have different prey requirements. An otter that specializes on snails may consume a higher number of prey items per dive, but the nutritional value and edible biomass per unit is less than an otter eating crab (Oftedal et al., 2007). However, crab specialists may require more dives (use more energy) to acquire that crab (Tinker, Costa, Estes, \& Wieringa, 2007). It is also important to note that our energetic cost estimates are probably conservative. They reflect the immediate costs of activity increase in response to a disturbance, and do not include the latent costs of successful and unsuccessful foraging attempts. Additional prey requirements will also influence activity budgets, increasing required foraging time and reducing rest time. Meeting this challenge could be particularly difficult for reproductive females, which are already allotting the maximum possible time foraging (Thometz et al., 2016). 
We report energetic costs for average male and average independent females, and not for reproductive females, due to the nature of our observational scans. Although females and pups were identified, reproductive females were not followed and identified between scans. Therefore, specific behaviors across time of a reproductive female were not identified, merely pup presence with relation to an individual. If we were to consider reproductive females, we expect that their disturbance costs could be higher than an average male, because their energetic demands nearly double during lactation and pup care (Chinn et al., 2016; Elliott Smith, Newsome, Estes, \& Tinker, 2015; Thometz et al., 2014). The additional energetic demands of reproductive females can lead to massive depletion of energy reserves, called end-lactation syndrome, a condition which results in additional maternal deaths per year (Chinn et al., 2016). Elevated energetic costs and loss of energy reserves makes reproductive females extremely vulnerable to 'caloric insufficiency'(Chinn et al., 2016). Reproductive female sea otters subjected to chronic human disturbance may therefore be particularly at-risk: the added energetic costs of disturbance, combined with end-lactation syndrome, may push reproductive females to their energetic limits and possible death (Chinn et al., 2016; Elliott Smith et al., 2015; Thometz et al., 2014). Our results provide a foundation for quantifying energetic costs of disturbance: future research could focus on how reproductive females are impacted by disturbance, furthering our understanding of how increased human recreation affects sea otter populations. 


\section{Conclusion}

As our coastal communities grow, human-wildlife encounters are inevitable. This project used new methods to expand our knowledge of the impacts of human disturbance on wildlife, by quantifying energetic costs and exploring the implications of these costs for the sea otter populations. We determined that sea otters experience an energetic cost to disturbance that varies by location and distance to stimuli. A stochastic model that predicts sea otter activity and consequent energetic cost based on disturbance distance provides a useful tool for regulatory agencies to implement policies to manage human disturbance on sea otters. 


\section{References}

Altmann, J. (1974). Observational study of behavior : sampling methods. Behaviour, 49(3), 227-267.

Beale, C. M. (2007). The behavioral ecology of disturbance responses. International Journal of Comparative Psychology, 20(2), 111-120.

Bejder, L., Samuels, A., Whitehead, H., Finn, H., \& Allen, S. (2009). Impact assessment research: use and misuse of habituation, sensitisation and tolerance in describing wildlife responses to anthropogenic stimuli. Marine Ecology Progress Series, 395 , $177-185$.

Bejder, Lars, Samuels, A., Whitehead, H., \& Gales, N. (2006). Interpreting short-term behavioural responses to disturbance within a longitudinal perspective. Animal Behaviour, (72.5), 1149-1158.

Benham, D. (2006). A Multidisciplinary Approach to Investigating and Managing the Disturbance of Southern Sea Otters ( Enhydra lutris nereis) by Recreational Activities (master's thesis). University of Nottingham, Nottingham, United Kingdom.

Chinn, S. M., Miller, M. A., Tinker, M. T., Staedler, M. M., Batac, F. I., Dodd, E. M., \& Henkel, L. A. (2016). The high cost of motherhood: end-lactation syndrome in southern sea otters ( Enhydra Lutris Nereis ) on the Central California, USA, Coast. Journal of Wildlife Diseases, 52(2), 307-318.

Culik, B., Adelung, D., \& Woakes, A. J. (1990). The effect of disturbance on the heart rate and behavior of adelie penguins (Pygoscelis adeliae) during the breeding season. In K. R. Kerry \& G. Hempel (Eds.), Antarctic Ecosystems: Ecological Change and Conservation (pp. 177-180). New York: Springer.

Curland, J. M. (1997). Effects of disturbance on sea otters (Enhydra lutris) near Monterey, California (master's thesis). San Jose State University, San Jose, United States.

Dantzer, B., Fletcher, Q. E., Boonstra, R., \& Sheriff, M. J. (2014). Measures of physiological stress : a transparent or opaque window into the status, management and conservation of species?. Conservation Physiology, 2(1).

Smith, E. A. E., Newsome, S. D., Estes, J. A., \& Tinker, M. T. (2015). The cost of reproduction: differential resource specialization in female and male California sea otters. Oecologia, 178(1), 17-29. 
Gelman, A., Carlin, J. B., Stern, H. S., Dunson, D. B., Vehtari, A., \& Rubin, D. B. (2014). Bayesian Data Analysis (Vol. 2). Boca Raton, FL: CRC press.

Gelman, Andrew. (2006). Prior distributions for variance parameters in hierarchical models ( Comment on Article by Browne and Draper ). Bayesian Analysis, 1(3), $515-534$.

Gelman, A., Jakulin, A., \& Grazia, M. (2008). A weakly informative default prior distribution for logistic and other regression models. The Annals of Applied Statistics, 2(4), 1360-1383.

Hill, R. W., Wyse, G. A., \& Anderson, M. (2004). Animal Physiology (Vol. 2). Sunderland, Massachusetts: Sinauer Associates.

Houston, A. I., Prosser, E., \& Sans, E. (2012). The cost of disturbance: a waste of time and energy? Oikos, 121(4), 597-604.

Hoyt, E. (2001). Whale watching 2001: Worldwide tourism numbers, expenditures, and expanding socioeconomic benefits. Yarmouth Port, Massachusetss: International Fund for Animal Welfare.

Lunn, N. J., Stirling, I., Andriashek, D., \& Richardson, E. (2004). Selection of maternity dens by female polar bears in western Hudson Bay, Canada and the effects of human disturbance. Polar Biology, 27(6), 350-356.

Lusseau, D., Bain, D. E., Williams, R., \& Smith, J. C. (2009). Vessel traffic disrupts the foraging behavior of southern resident killer whales (Orcinus orca). Endangered Species Research, 6(3), 211-221.

Martin, J., Basille, M., Van Moorter, B., Kindberg, J., Allainé, D., \& Swenson, J. E. (2010). Coping with human disturbance: spatial and temporal tactics of the brown bear ( Ursus arctos ). Canadian Journal of Zoology, 88(9), 875-883.

Nisbet, I. A. N. C. T. (2000). Disturbance, habituation and management of waterbird colonies. Waterbirds, 23, 312-332.

Nowacek, S. M., \& Wells, R. S. (2001). Short-term effects of boat traffic on bottlenose dolphins, Turciops truncatus, in Sarasota bay, Florida. Marine Mammal Science, 17(4), 673-688. 
Oftedal, O. T., Ralls, K., Tinker, M. T., \& Green, A. (2007). Nutritional constraints in the southern sea otter in the Monterey National Marine Sanctuary and a comparison to sea otter populations at San Nicolas Island, California and Glacier Bay, Alaska. Joint Final Report to Monterey Bay National Marine Sanctuary. Monterey Bay National Marine Sanctuary, 263.

Riedman, M. L., \& Estes, J. A. (1990). The sea otter, Enhydra lutris: behavior, ecology and natural history. US Fish and Wildlife Service Biological Report, 90(1-3), 1-126.

Sorice, M. G., Shafer, C. S., \& Scott, D. (2003). Managing endangered species within the use/preservation paradox: Understanding and defining harassment of the West Indian manatee (Trichechus manatus). Coastal Management, 31(4), 319-338.

Tarlow, E. M., \& Blumstein, D. T. (2007). Evaluating methods to quantify anthropogenic stressors on wild animals. Applied Animal Behaviour Science, 102(3-4), 429-451.

Taylor, S. (2017). Markov Models: An Introduction to Markov Models. San Bernadino, California: CreateSpace Independent Publishing Platform.

The Endangered Species Act of 1973. (1973). Washington: U.S. Government Publishing Office.

The Marine Mammal Protection Act of 1972. (1972). Washington: U.S. Government Publishing Office.

Thometz, N. M., Staedler, M. M., Tomoleoni, J. A., Bodkin, J. L., Bentall, G. B., \& Tinker, M. T. (2016). Trade-offs between energy maximization and parental care in a central place forager, the sea otter. Behavioral Ecology, 27(5), 1552-1566.

Thometz, N. M., Tinker, M. T., Staedler, M. M., Mayer, K. A., \& Williams, T. M. (2014). Energetic demands of immature sea otters from birth to weaning: implications for maternal costs, reproductive behavior and population-level trends. Journal of Experimental Biology, 217(12), 2053-2061.

Tinker, M. T., Bentall, G., \& Estes, J. A. (2008). Food limitation leads to behavioral diversification and dietary specialization in sea otters. Proceedings of the National Academy of Sciences, 105(2), 560-565.

Tinker, M. T., Costa, D. P., Estes, J. A., \& Wieringa, N. (2007). Individual dietary specialization and dive behaviour in the California sea otter: using archival timedepth data to detect alternative foraging strategies. Deep Sea Research Part II: Topical Studies in Oceanography, 54(3-4), 330-342. 
Weimerskirch, H., Shaffer, S. a, Mabille, G., Martin, J., Boutard, O., \& Rouanet, J. L. (2002). Heart rate and energy expenditure of incubating wandering albatrosses: basal levels, natural variation, and the effects of human disturbance. The Journal of Experimental Biology, 205, 475-483.

Williams, R., Lusseau, D., \& Hammond, P. S. (2006). Estimating relative energetic costs of human disturbance to killer whales (Orcinus orca). Biological Conservation, 133(3), 301-311.

Williams, T. M. (1989). Swimming by sea otters: adaptations for low energetic cost locomotion. Journal of Comparative Physiology A, 164(6), 815-824.

Yeates, L. C., Williams, T. M., \& Fink, T. L. (2007). Diving and foraging energetics of the smallest marine mammal, the sea otter (Enhydra lutris). Journal of Experimental Biology, 210(11), 1960-1970. 


\section{Appendix}

Appendix 1. Fitted parameter values

\begin{tabular}{|c|c|}
\hline & Fitted values \\
\hline Mean Expected Activity $(A \exp i, j, t)$ & 1.0019 \\
\hline Mean Activity Pup (Xi,j,t Pup) & 1.0012 \\
\hline Mean Activity Kelp $(X i, j, t$ Kelp) & 1.0021 \\
\hline Mean Activity Group Size (Xi,j,t Grpsz) & 1.0005 \\
\hline Mean Activity Early Afternoon (Xi,j,t PM1) & 1.0006 \\
\hline Mean Activity Late Afternoon (Xi,j,t $P M 2)$ & 1.0001 \\
\hline Mean Activity based on Location & 1.0021 \\
\hline Vulnerability Function $f V$ & 1.0006 \\
\hline Vulnerability Parameter $\beta 1^{*}$ Grpsz & 1.0006 \\
\hline Vulnerability Parameter $\beta 2 *$ Pup & 1.0012 \\
\hline Vulnerability Parameter $\beta 3^{*}$ Kelp & 1.0025 \\
\hline Vulnerability Parameter $\beta 0 \mathrm{j}$ (location) & 1.0011 \\
\hline Parameter $\phi \mathrm{j}$ & 1.0011 \\
\hline Parameter $\theta$ & 1.0057 \\
\hline Parameter $\sigma(\mathrm{A})$ & 1.0002 \\
\hline Parameter $\sigma(\mathrm{B})$ & 1.0003 \\
\hline Parameter $\sigma(\mathrm{P})$ & 1.0021 \\
\hline Parameter $\sigma(D)$ & 1.0023 \\
\hline Parameter $\eta$ & 1.0055 \\
\hline Parameter $\rho$ & 1.0006 \\
\hline Parameter $\alpha$ & 1.0006 \\
\hline
\end{tabular}


Appendix 2. (A) Relative Disturbance Effect (RDE) Mean values and 95\% CI for Sites. (B) RDE Mean Values and 95\% CI for locations.

\section{A)}

\begin{tabular}{|l|c|c|c|c|c|c|c|c|c|}
\hline SITE & JTTY & \multicolumn{1}{|c|}{ SEBE } & WILD & CARO & OP & HOPK & MBCT & MBTP & MBHM \\
\cline { 2 - 9 } MEAN RDE & 0.268 & 0.180 & 0.164 & 0.231 & 0.192 & 0.259 & 0.041 & 0.107 & 0.115 \\
95\% Cl HIGH & 0.350 & 0.336 & 0.334 & 0.328 & 0.308 & 0.458 & 0.081 & 0.229 & 0.298 \\
95\% CI LOW & 0.178 & -0.017 & -0.090 & 0.121 & 0.057 & 0.039 & 0.005 & 0.011 & -0.032 \\
\hline
\end{tabular}

B)

\begin{tabular}{|l|c|c|c|}
\hline LOCATION & Moss Landing & Monterey & Morro Bay \\
\cline { 2 - 4 } MEAN RDE & 0.2042 & 0.2201 & 0.0994 \\
95\% CI HIIGH & 0.3325 & 0.3530 & 0.2178 \\
95\% CI LOW & 0.0485 & 0.0699 & 0.0014 \\
\hline
\end{tabular}

Appendix 3. (A) Relative Disturbance Effect (RDE) Mean values and 95\% CI for covariates. (B) Mean Expected Activity for covariates.

A)

\begin{tabular}{|c|c|c|c|c|c|c|c|c|c|c|}
\hline \multirow{4}{*}{ 峁 } & Covariate & GroupSize 20 & GroupSize 1 & Pup Ratio 1 & Pup Ratio 0 & Kelp 1 & Kelp 0 & Morning & Early Aft. & Late Aft. \\
\hline & MEAN & 0.196 & 0.240 & 0.207 & 0.223 & 0.259 & 0.176 & 0.220 & 0.220 & 0.220 \\
\hline & $\mathrm{Cl} \mathrm{HI}$ & 0.329 & 0.340 & 0.345 & 0.332 & 0.356 & 0.316 & 0.329 & 0.329 & 0.329 \\
\hline & CI LO & 0.047 & 0.131 & 0.044 & 0.105 & 0.155 & 0.025 & 0.101 & 0.101 & 0.101 \\
\hline
\end{tabular}

B)

\begin{tabular}{|c|c|c|c|c|c|c|c|c|c|c|}
\hline \multirow{4}{*}{ 它 } & Covariate & GroupSize 20 & GroupSize 1 & Pup Ratio 1 & Pup Ratio 0 & Kelp 1 & Kelp 0 & Morning & Early Aft. & Late Aft. \\
\hline & MEAN & 0.105 & 0.276 & 0.142 & 0.193 & 0.088 & 0.328 & 0.179 & 0.166 & 0.230 \\
\hline & $\mathrm{ClHI}$ & 0.157 & 0.376 & 0.217 & 0.276 & 0.131 & 0.448 & 0.256 & 0.241 & 0.323 \\
\hline & CILO & 0.065 & 0.189 & 0.084 & 0.127 & 0.055 & 0.227 & 0.117 & 0.108 & 0.152 \\
\hline
\end{tabular}

Appendix 4. The Relative Potential Disturbance Effect (PD) for sea otters given different locations and distances. Distances are in meters (m). Distances that exceed $100 \mathrm{~m}$ are not displayed.

\begin{tabular}{|c|c|c|c|c|}
\hline & $0.05 \mathrm{PD}$ & $0.1 \mathrm{PD}$ & $0.2 \mathrm{PD}$ & $0.3 \mathrm{PD}$ \\
\hline Location & Distance $(\mathrm{m})$ & Distance (m) & Distance (m) & Distance (m) \\
\hline Moss Landing & --- & 78.83 & 34.43 & 21.33 \\
\hline Monterey & -- & -- & 48.05 & 27.32 \\
\hline Morro Bay & 45.25 & 27.43 & 16.68 & 12.71 \\
\hline Average & -- & 54.31 & 26.66 & 17.75 \\
\hline
\end{tabular}


Appendix 5. Daily Energetic Costs (kJ) for an average $27.7 \mathrm{~kg}$ male sea otter (black) and $19.89 \mathrm{~kg}$ female sea otter (grey) with 95\% CI for (A) Moss Landing (B) Monterey (C) Morro Bay.

A)

\begin{tabular}{|c|c|c|c|c|c|c|c|c|c|c|c|c|c|c|}
\hline \multirow{3}{*}{\multicolumn{2}{|c|}{$\begin{array}{c}\text { Distance } \\
(\mathrm{m})\end{array}$}} & \multirow{3}{*}{ kJ } & \multicolumn{12}{|c|}{ Disturbance Frequency } \\
\hline & & & \multicolumn{2}{|r|}{2} & \multicolumn{2}{|c|}{4} & & & \multicolumn{2}{|c|}{10} & \multicolumn{2}{|c|}{12} \\
\hline & & & Male & Female & Male & Female & Male & Female & Male & Female & Male & Female & Male & Female \\
\hline \multirow{4}{*}{\multicolumn{2}{|c|}{10}} & MEAN & 91.98 & 66.10 & 183.40 & 127.18 & 260.81 & 189.91 & 351.27 & 253.49 & 424.10 & 309.71 & 511.23 & 367.10 \\
\hline & & 95\%Cl High & 96.01 & 69.12 & 189.09 & 131.07 & 267.15 & 194.79 & 358.44 & 259.08 & 431.92 & 315.72 & 519.63 & 373.78 \\
\hline & & $95 \% \mathrm{Cl}$ Low & 87.95 & 63.08 & 177.71 & 123.29 & 254.47 & 185.02 & 344.10 & 247.89 & 416.27 & 303.70 & 502.84 & 360.42 \\
\hline & & SD & 64.98 & 48.76 & 91.74 & 62.74 & 102.17 & 78.75 & 115.58 & 90.20 & 126.19 & 96.87 & 135.38 & 107.71 \\
\hline \multirow{4}{*}{\multicolumn{2}{|c|}{15}} & MEAN & 66.92 & 49.12 & 133.40 & 94.93 & 202.06 & 140.94 & 264.18 & 186.73 & 322.60 & 232.04 & 383.13 & 273.07 \\
\hline & & $95 \% \mathrm{Cl}$ High & 69.89 & 51.37 & 137.62 & 97.88 & 207.13 & 144.57 & 269.73 & 190.94 & 328.92 & 236.61 & 389.56 & 277.95 \\
\hline & & 95\%Cl Low & 63.95 & 46.86 & 129.18 & 91.97 & 196.99 & 137.31 & 258.63 & 182.53 & 316.27 & 227.48 & 376.70 & 268.20 \\
\hline & & SD & 47.84 & 36.35 & 68.09 & 47.65 & 81.73 & 58.50 & 89.44 & 67.80 & 101.98 & 73.59 & 103.64 & 78.68 \\
\hline & \multirow{4}{*}{20} & MEAN & 56.34 & 38.63 & 107.24 & 78.56 & 160.07 & 113.96 & 213.39 & 153.77 & 258.54 & 187.80 & 305.80 & 221.34 \\
\hline & & $95 \% \mathrm{Cl}$ High & 58.79 & 40.37 & 110.66 & 81.06 & 164.12 & 116.95 & 217.94 & 157.22 & 263.31 & 191.58 & 311.07 & 225.42 \\
\hline & & $\% \mathrm{Cl}$ Low & 53.89 & 36.89 & 103.83 & 76.07 & 156.03 & 110.98 & 208.83 & 150.31 & 253.76 & 184.03 & 300.53 & 217.25 \\
\hline & & SD & 39.47 & 27.99 & 55.12 & 40.27 & 65.24 & 48.17 & 73.50 & 55.68 & 77.01 & 60.86 & 84.98 & 65.84 \\
\hline & \multirow{4}{*}{25} & IEAN & 46.12 & 34.20 & 91.26 & 65.63 & 135.46 & 99.30 & 179.05 & 127.84 & 220.92 & 161.14 & 267.23 & 188.99 \\
\hline & & $95 \% \mathrm{Cl} \mathrm{High}$ & 48.13 & 35.70 & 94.24 & 67.70 & 138.83 & 101.81 & 182.92 & 130.72 & 225.10 & 164.31 & 271.85 & 192.39 \\
\hline & & $95 \% \mathrm{Cl}$ Low & 44.12 & 32.70 & 88.28 & 63.55 & 132.09 & 96.79 & 175.17 & 124.96 & 216.75 & 157.98 & 262.61 & 185.60 \\
\hline & & SD & 32.39 & 24.23 & 48.05 & 33.53 & 54.32 & 40.47 & 62.53 & 46.47 & 67.30 & 51.07 & 74.51 & 54.77 \\
\hline & \multirow{4}{*}{30} & MEAN & 41.85 & 29.95 & 80.31 & 57.73 & 120.98 & 86.12 & 156.19 & 112.97 & 193.63 & 141.28 & 231.08 & 163.57 \\
\hline 2 & & $95 \% \mathrm{Cl}$ High & 43.68 & 31.33 & 82.77 & 59.61 & 123.96 & 88.41 & 159.48 & 115.55 & 197.17 & 144.09 & 235.01 & 166.57 \\
\hline & & $95 \%$ Cl Low & 40.02 & 28.57 & 77.84 & 55.85 & 117.99 & 83.82 & 152.90 & 110.39 & 190.09 & 138.47 & 227.14 & 160.58 \\
\hline L & & SD & 29.54 & 22.21 & 39.78 & 30.35 & 48.09 & 36.98 & 53.08 & 41.59 & 57.08 & 45.26 & 63.45 & 48.32 \\
\hline & \multirow{4}{*}{35} & IEAN & 35.99 & 26.11 & 70.15 & 51.47 & 105.71 & 78.38 & 141.28 & 102.02 & 173.10 & 122.96 & 206.11 & 147.06 \\
\hline & & $95 \% \mathrm{Cl}$ High & 37.57 & 27.30 & 72.24 & 53.18 & 108.42 & 80.47 & 144.27 & 104.33 & 176.31 & 125.48 & 209.60 & 149.79 \\
\hline & & $95 \%$ Cl Low & 34.42 & 24.91 & 68.06 & 49.76 & 102.99 & 76.29 & 138.29 & 99.72 & 169.88 & 120.44 & 202.61 & 144.33 \\
\hline & & St & 25.40 & 19.21 & 33.69 & 27.62 & 43.77 & 33.74 & 48.23 & 37.15 & 51.83 & 40.64 & 56.39 & 44.04 \\
\hline & \multirow{4}{*}{40} & MEAN & 32.64 & 24.20 & 63.04 & 45.87 & 96.29 & 68.63 & 126.15 & 91.99 & 157.57 & 114.84 & 186.37 & 134.24 \\
\hline & & 95\%Cl High & 34.07 & 25.28 & 65.01 & 47.29 & 98.68 & 70.31 & 128.87 & 94.06 & 160.59 & 117.13 & 189.50 & 136.58 \\
\hline & & $95 \% \mathrm{Cl}$ Low & 31.22 & 23.13 & 61.07 & 44.44 & 93.91 & 66.95 & 123.43 & 89.92 & 154.55 & 112.55 & 183.24 & 131.90 \\
\hline & & $S D$ & 22.94 & 17.35 & 31.81 & 22.99 & 38.48 & 27.12 & 43.91 & 33.39 & 48.69 & 36.94 & 50.49 & 37.67 \\
\hline & \multirow{4}{*}{45} & EAN & 30.22 & 21.48 & 59.80 & 41.09 & 86.00 & 62.84 & 112.17 & 81.84 & 144.05 & 102.98 & 172.59 & 121.96 \\
\hline & & $95 \% \mathrm{Cl}$ High & 31.50 & 22.46 & 61.69 & 42.44 & 88.25 & 64.42 & 114.68 & 83.75 & 146.74 & 105.08 & 175.61 & 124.23 \\
\hline & & 95\%Cl Low & 28.93 & 20.50 & 57.91 & 39.74 & 83.74 & 61.25 & 109.66 & 79.93 & 141.37 & 100.87 & 169.57 & 119.70 \\
\hline & & $\underline{U}$ & 20.77 & 15.81 & 30.49 & 21.80 & 36.35 & 25.56 & 40.41 & 30.85 & 43.28 & 33.97 & 48.72 & 36.54 \\
\hline & \multirow{4}{*}{50} & EAN & 27.62 & 20.05 & 54.36 & 39.34 & 82.27 & 57.77 & 107.50 & 76.34 & 132.49 & 97.04 & 158.14 & 114.77 \\
\hline & & $95 \% \mathrm{Cl}$ High & 28.83 & 20.95 & 56.09 & 40.59 & 84.30 & 59.23 & 109.78 & 78.11 & 135.09 & 98.93 & 160.77 & 116.93 \\
\hline & & $95 \%$ Cl Low & 26.41 & 19.15 & 52.63 & 38.10 & 80.23 & 56.31 & 105.22 & 74.58 & 129.90 & 95.14 & 155.50 & 112.60 \\
\hline & & SD & 19.49 & 14.52 & 27.87 & 20.10 & 32.78 & 23.54 & 36.72 & 28.42 & 41.81 & 30.57 & 42.54 & 34.87 \\
\hline
\end{tabular}


B)

\begin{tabular}{|c|c|c|c|c|c|c|c|c|c|c|c|c|c|c|}
\hline \multirow{3}{*}{\multicolumn{2}{|c|}{\begin{tabular}{|l|l} 
Distance \\
$(\mathrm{m})$
\end{tabular}}} & \multirow{3}{*}{$\mathrm{kJ}$} & \multicolumn{12}{|c|}{ Disturbance Frequency } \\
\hline & & & \multicolumn{2}{|c|}{2} & \multicolumn{2}{|c|}{4} & \multicolumn{2}{|c|}{6} & \multicolumn{2}{|c|}{8} & \multicolumn{2}{|c|}{10} & \multicolumn{2}{|c|}{12} \\
\hline & & & Male & Female & Male & Female & Male & Female & Male & Female & Male & Female & Male & Female \\
\hline \multirow{4}{*}{\multicolumn{2}{|c|}{10}} & MEAN & 112.98 & 80.35 & 217.10 & 158.83 & 322.68 & 225.25 & 421.25 & 301.62 & 506.29 & 375.24 & 599.12 & 432.87 \\
\hline & & $95 \% \mathrm{Cl}$ High & 117.87 & 83.85 & 223.62 & 163.74 & 330.32 & 230.84 & 429.91 & 308.34 & 515.70 & 382.36 & 608.79 & 440.95 \\
\hline & & $95 \% \mathrm{Cl}$ Low & 108.10 & 76.85 & 210.57 & 153.92 & 315.04 & 219.66 & 412.60 & 294.89 & 496.87 & 368.13 & 589.44 & 424.80 \\
\hline & & SD & 78.77 & 56.41 & 105.23 & 79.12 & 123.21 & 90.11 & 139.62 & 108.44 & 151.78 & 114.75 & 156.04 & 130.19 \\
\hline \multirow{4}{*}{\multicolumn{2}{|c|}{15}} & MEAN & 85.13 & 63.91 & 168.67 & 121.46 & 249.04 & 180.86 & 332.62 & 240.87 & 409.35 & 294.82 & 480.73 & 347.91 \\
\hline & & $95 \% \mathrm{Cl}$ High & 88.82 & 66.75 & 173.60 & 125.23 & 255.06 & 185.54 & 339.42 & 245.99 & 416.66 & 300.61 & 488.66 & 354.11 \\
\hline & & $95 \% \mathrm{Cl}$ Low & 81.45 & 61.08 & 163.74 & 117.68 & 243.01 & 176.19 & 325.82 & 235.75 & 402.03 & 289.03 & 472.80 & 341.71 \\
\hline & & SD & 59.38 & 45.68 & 79.55 & 60.94 & 97.16 & 75.38 & 109.67 & 82.56 & 118.01 & 93.38 & 127.85 & 99.98 \\
\hline \multirow{4}{*}{ 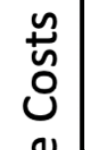 } & \multirow{4}{*}{20} & MEAN & 73.16 & 53.33 & 145.87 & 103.25 & 210.10 & 150.42 & 275.73 & 203.52 & 344.21 & 249.27 & 408.94 & 289.41 \\
\hline & & $95 \% \mathrm{Cl}$ High & 76.41 & 55.75 & 150.34 & 106.49 & 215.11 & 154.30 & 281.61 & 207.82 & 350.37 & 254.00 & 415.34 & 294.69 \\
\hline & & $95 \% \mathrm{Cl}$ Low & 69.92 & 50.91 & 141.40 & 100.01 & 205.09 & 146.53 & 269.85 & 199.21 & 338.04 & 244.55 & 402.54 & 284.12 \\
\hline & & SD & 52.38 & 38.98 & 72.08 & 52.29 & 80.78 & 62.62 & 94.83 & 69.37 & 99.41 & 76.26 & 103.23 & 85.19 \\
\hline \multirow{6}{*}{ 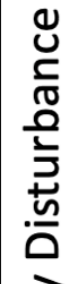 } & \multirow{4}{*}{25} & MEAN & 66.13 & 46.37 & 127.87 & 93.44 & 182.52 & 133.12 & 245.45 & 177.21 & 294.38 & 222.29 & 358.79 & 254.52 \\
\hline & & $95 \% \mathrm{Cl}$ High & 68.93 & 48.50 & 131.79 & 96.20 & 186.97 & 136.54 & 250.37 & 180.97 & 300.05 & 226.75 & 364.67 & 259.19 \\
\hline & & $95 \% \mathrm{Cl}$ Low & 63.33 & 44.24 & 123.94 & 90.68 & 178.08 & 129.70 & 240.53 & 173.45 & 288.71 & 217.83 & 352.91 & 249.85 \\
\hline & & SD & 45.10 & 34.32 & 63.29 & 44.51 & 71.63 & 55.18 & 79.31 & 60.58 & 91.45 & 71.92 & 94.83 & 75.30 \\
\hline & \multirow{4}{*}{30} & MEAN & 56.85 & 39.79 & 117.27 & 80.82 & 163.47 & 118.44 & 217.86 & 159.94 & 266.43 & 196.12 & 316.43 & 227.87 \\
\hline & & $95 \% \mathrm{Cl}$ High & 59.35 & 41.60 & 120.66 & 83.34 & 167.62 & 121.44 & 222.39 & 163.36 & 271.36 & 199.82 & 322.00 & 231.86 \\
\hline \multirow{11}{*}{\multicolumn{2}{|c|}{ 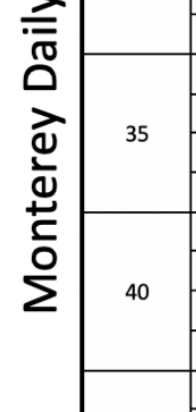 }} & $95 \% \mathrm{Cl}$ Low & 54.35 & 37.99 & 113.89 & 78.30 & 159.33 & 115.45 & 213.32 & 156.53 & 261.50 & 192.42 & 310.85 & 223.89 \\
\hline & & SD & 40.33 & 29.10 & 54.57 & 40.62 & 66.82 & 48.29 & 73.10 & 55.05 & 79.54 & 59.68 & 89.91 & 64.21 \\
\hline & & MEAN & 54.42 & 36.67 & 102.18 & 73.12 & 151.84 & 112.39 & 200.66 & 141.22 & 245.82 & 176.48 & 292.44 & 210.66 \\
\hline & & $95 \% \mathrm{Cl}$ High & 56.83 & 38.36 & 105.20 & 75.39 & 155.52 & 115.18 & 204.74 & 144.37 & 250.44 & 179.84 & 297.38 & 214.31 \\
\hline & & $95 \% \mathrm{Cl}$ Low & 52.01 & 34.97 & 99.16 & 70.86 & 148.15 & 109.61 & 196.58 & 138.06 & 241.20 & 173.11 & 287.49 & 207.00 \\
\hline & & SD & 38.86 & 27.35 & 48.73 & 36.48 & 59.41 & 44.91 & 65.79 & 50.83 & 74.51 & 54.24 & 79.70 & 58.96 \\
\hline & & MEAN & 46.92 & 33.28 & 94.79 & 67.67 & 140.22 & 99.86 & 181.80 & 130.32 & 226.37 & 161.94 & 270.90 & 190.35 \\
\hline & & $95 \% \mathrm{Cl}$ High & 49.03 & 34.76 & 97.69 & 69.78 & 143.68 & 102.41 & 185.59 & 133.17 & 230.54 & 165.14 & 275.39 & 193.80 \\
\hline & & $95 \% \mathrm{Cl}$ Low & 44.81 & 31.81 & 91.89 & 65.55 & 136.76 & 97.31 & 178.02 & 127.47 & 222.21 & 158.74 & 266.41 & 186.90 \\
\hline & & SD & 34.02 & 23.73 & 46.71 & 34.13 & 55.81 & 41.18 & 61.06 & 46.00 & 67.17 & 51.56 & 72.41 & 55.61 \\
\hline & & MEAN & 44.60 & 32.20 & 87.06 & 63.65 & 130.00 & 93.96 & 167.96 & 124.35 & 210.63 & 152.22 & 250.66 & 179.98 \\
\hline \multirow{3}{*}{\multicolumn{2}{|c|}{45}} & $95 \% \mathrm{Cl}$ High & 46.51 & 33.61 & 89.75 & 65.75 & 133.28 & 96.45 & 171.50 & 127.13 & 214.62 & 155.20 & 254.70 & 183.07 \\
\hline & & $95 \% \mathrm{Cl}$ Low & 42.70 & 30.79 & 84.36 & 61.55 & 126.72 & 91.47 & 164.41 & 121.56 & 206.64 & 149.24 & 246.61 & 176.89 \\
\hline & & SD & 30.73 & 22.73 & 43.48 & 33.92 & 52.81 & 40.18 & 57.18 & 44.91 & 64.32 & 48.08 & 65.27 & 49.83 \\
\hline \multirow{4}{*}{\multicolumn{2}{|c|}{50}} & MEAN & 42.29 & 30.69 & 80.60 & 58.51 & 122.87 & 86.77 & 160.65 & 113.80 & 195.62 & 142.53 & 235.68 & 170.19 \\
\hline & & $95 \% \mathrm{Cl}$ High & 44.11 & 32.05 & 83.03 & 60.36 & 125.97 & 88.97 & 163.97 & 116.38 & 199.16 & 145.31 & 239.61 & 173.30 \\
\hline & & $95 \%$ Cl Low & 40.46 & 29.32 & 78.17 & 56.67 & 119.77 & 84.57 & 157.33 & 111.22 & 192.07 & 139.74 & 231.74 & 167.08 \\
\hline & & SD & 29.38 & 22.01 & 39.24 & 29.74 & 49.98 & 35.41 & 53.52 & 41.61 & 57.10 & 44.87 & 63.50 & 50.12 \\
\hline
\end{tabular}


C)

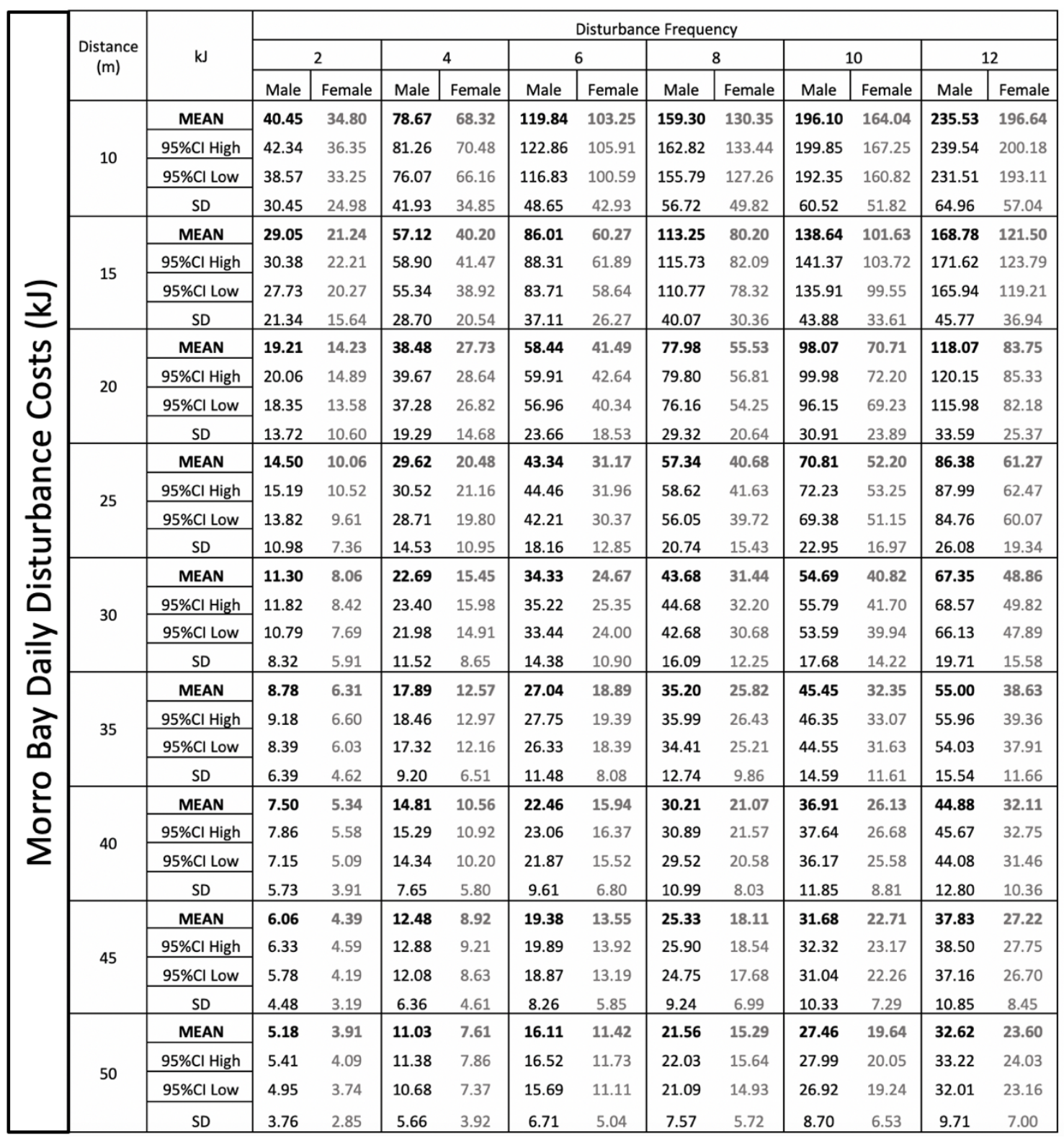

Appendix 6. Calculations for number of prey needed to account for daily energetic costs of disturbance for an average Male $(27.7 \mathrm{~kg})$.

MALE

\begin{tabular}{cccccc}
\hline Prey & $\mathrm{kcal} / \mathrm{g}$ & $\mathrm{g} \mathrm{edbl} / \mathrm{itm}$ & Net kcal & Disturbance Costs (kJ) & Num Prey Required \\
\hline Dungeness crabs & 0.75464526 & 184 & 138.8547278 & 50.78 & 0.365705949 \\
Littleneck clams & 0.535053553 & 8.9 & 4.761976623 & 50.78 & 10.66363908 \\
Turban snails & 1.021148555 & 2.5 & 2.552871388 & 50.78 & 19.89132717
\end{tabular}


Appendix 7. Based on binomial probability outcomes, the examples of probability of disturbing a resting sea otter given potential disturbance stimulus with associated effect size (relative disturbance effect) of 0.2 for 100 otters, given a mean activity sate of (A) 0.2 and (B) 0.8 .

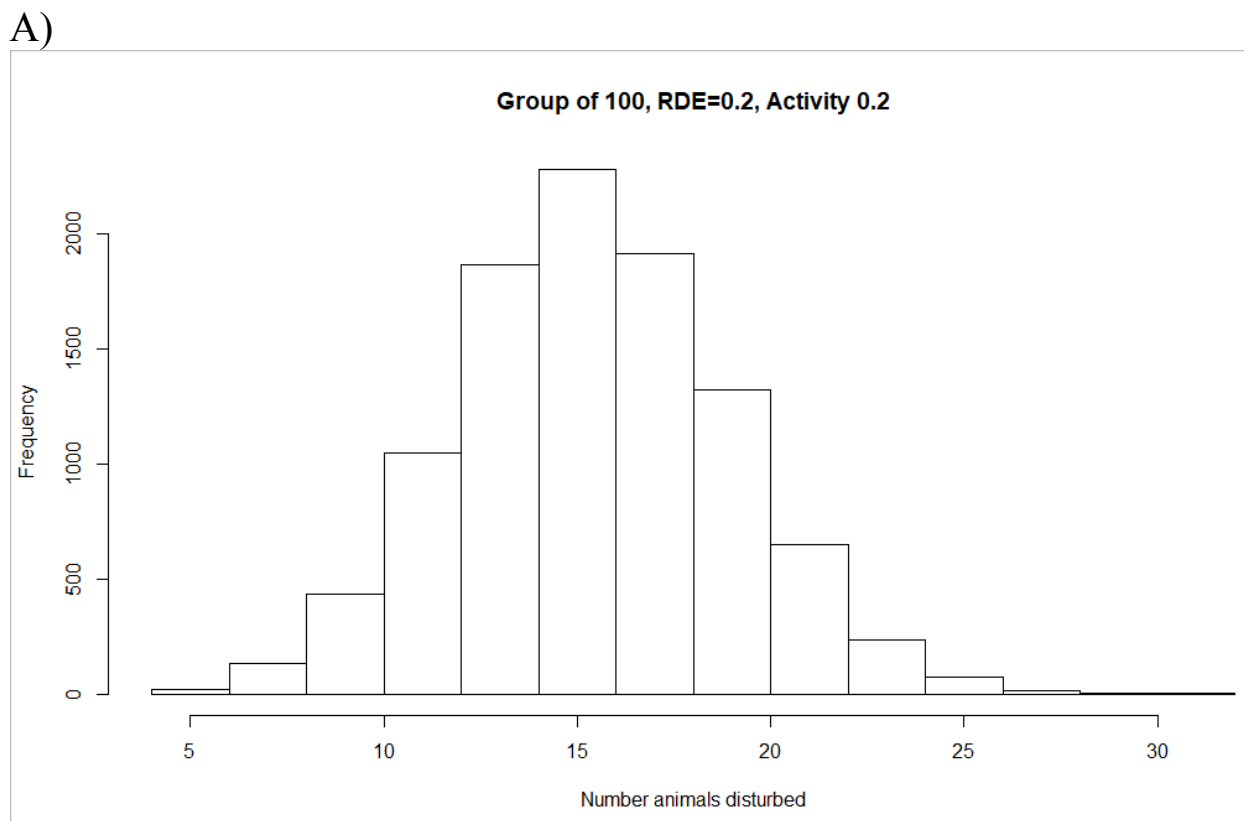

B)

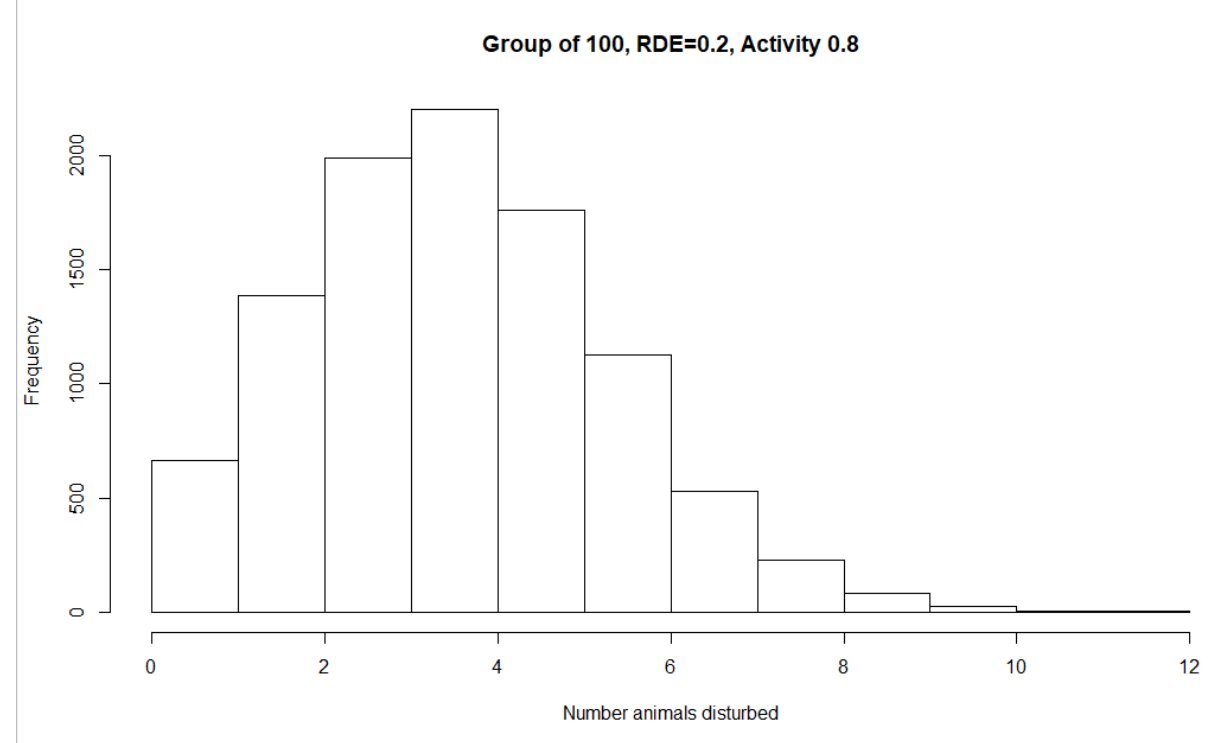

